\title{
The modulatory role of internet-supported mindfulness-based cognitive therapy on extracellular vesicles and psychological distress in people who have had cancer: a protocol for a two-armed randomized controlled study
}

Diana R. Pereira ${ }^{1,2,3,4^{*}}$ (D), Eunice R. Silva ${ }^{1,2,3,4^{*}}$, Carina Carvalho-Maia ${ }^{3,4,5}$, Sara Monteiro-Reis ${ }^{3,4,5}$, Catarina Lourenço ${ }^{3,4,5}$, Rita Calisto ${ }^{6,7}$, Ricardo João Teixeira ${ }^{8,9}$, Linda E. Carlson ${ }^{10}$, Genevieve Bart ${ }^{11}$, Seppo J. Vainio ${ }^{11}$, M. Goreti F. Sales ${ }^{12,13}$, Carmen Jerónimo $3,4,5,14$ and Rui Henrique $3,4,5,14,15$

\begin{abstract}
Background: Mindfulness-based interventions (MBls) have been used in oncology contexts as a promising tool with numerous benefits for various health-related and psychosocial outcomes. Despite the increasing popularity of MBIs, few randomized controlled trials (RCTs) have examined their effects upon biological parameters. Specifically, no previous study has examined the effects of MBIs on extracellular vesicles (EVs), which are potentially important markers of health, disease, and stress. Moreover, the lack of RCTs is even more limited within the context of technology-mediated MBls and long-term effects.
\end{abstract}

* Correspondence: diana.r.pereira@gmail.com; esilva@ipoporto.min-saude.pt ${ }^{1}$ Psychology Service, Portuguese Oncology Institute of Porto (IPOP), Rua Dr. António Bernardino de Almeida, 4200-072 Porto, Portugal

Full list of author information is available at the end of the article

(c) The Author(s). 2022 Open Access This article is licensed under a Creative Commons Attribution 4.0 International License, which permits use, sharing, adaptation, distribution and reproduction in any medium or format, as long as you give appropriate credit to the original author(s) and the source, provide a link to the Creative Commons licence, and indicate if changes were made. The images or other third party material in this article are included in the article's Creative Commons licence, unless indicated otherwise in a credit line to the material. If material is not included in the article's Creative Commons licence and your intended use is not permitted by statutory regulation or exceeds the permitted use, you will need to obtain permission directly from the copyright holder. To view a copy of this licence, visit http://creativecommons.org/licenses/by/4.0/ The Creative Commons Public Domain Dedication waiver (http://creativecommons.org/publicdomain/zero/1.0/) applies to the data made available in this article, unless otherwise stated in a credit line to the data. 
Methods: The current study protocol presents a two-arm, parallel, randomized controlled study investigating the effects of internet-supported mindfulness-based cognitive therapy (MBCT) compared with treatment as usual (TAU). Primary outcomes are psychological distress and EV cargo of distressed participants with previous breast, colorectal, or prostate cancer diagnoses. Secondary outcomes are self-reported psychosocial and health-related measures, and additional biological markers. Outcomes will be assessed at baseline, 4 weeks after baseline (mid-point of the intervention), 8 weeks after baseline (immediately post-intervention), 24 weeks after baseline (after booster sessions), and 52 weeks after baseline. Our goal is to recruit at least 111 participants who have been diagnosed with breast, prostate, or colorectal cancer (cancer stage I to III), are between 18 and 65 years old, and have had primary cancer treatments completed between 3 months and 5 years ago. Half of the participants will be randomized to the TAU group, and the other half will participate in an 8-week online MBCT intervention with weekly group sessions via videoconference. The intervention also includes asynchronous homework, an online retreat after the fifth week, and 4 monthly booster sessions after completion of the 8-week programme.

Discussion: This study will allow characterizing the effects of internet-based MBCT on psychosocial and biological indicators in the context of cancer. The effects on circulating EVs will also be investigated, as a possible neurobiological pathway underlying mind-body intervention effects.

Trial registration: ClinicalTrials.gov NCT04727593 (date of registration: 27 January 2021; date of record verification: 6 October 2021).

Keywords: Cancer, Distress, Extracellular vesicles, Internet, Online, Mindfulness-based cognitive therapy, Mindfulness-based intervention, Randomized controlled trial

\section{Introduction}

Cancer remains one of the leading causes of death and accounted for 19.3 million new cases and 9.9 million deaths worldwide in 2020 [1, 2]. By 2040, these numbers are expected to increase to 30.3 million new cases and 16.3 million deaths [2]. However, survival rates are also increasing due to major advances in cancer diagnosis, treatment, and follow-up, which means that cancer will increasingly impact the lives of many people. This creates a need to control disease progression and recovery pathways to optimize the well-being, quality of life, and daily functioning of people with cancer.

Distress is among the main factors that negatively affect the quality of life of cancer patients, regardless of the type of cancer or the stage of disease progression [3-6]. It is defined as an unpleasant affective experience that affects psychological (cognitive/behavioural/emotional), physical, social, and/or spiritual domains of functioning. As a result, the ability to cope with the illness experience is severely impaired [7, 8]. Distress involves various experiences (e.g. anxiety; depression; fear; rumination) that vary from person to person and over time [5, 7]. Importantly, this is a common experience in people with cancer from the time of diagnosis through disease remission and long-term survivorship [4]. Hence, distress management becomes crucial but encounters numerous barriers, including underestimation of psychosocial needs and the stigma of receiving psychosocial support. Accordingly, many sufferers do not acknowledge their distress or avoid seeking professional help $[8,9]$.
Mindfulness-based interventions (MBIs) have been investigated as a viable approach to managing cancer distress and have become increasingly popular over the last two decades [10, 11]. These interventions are derived from ancient Buddhist meditation practices. They focus on bringing attention to the present moment, in an intentional, open, non-reactive, and non-judgmental way [12]. They aim to cultivate an attitude of observation, patience, and acceptance toward negative stressful experiences, rumination, and anxiety, rather than an attitude of judgment and avoidance [13].

In the context of cancer, the commonly used MBIs are mindfulness-based stress reduction (MBSR), mindfulnessbased cognitive therapy (MBCT), and mindfulness-based cancer recovery (MBCR) [14]. These MBIs may include a variety of formal mindfulness meditation practices, such as body scan, sitting, and walking meditation, as well as informal practices that promote the integration of mindfulness strategies into daily routines, such as observing body sensations and bringing awareness into routine activities [15]. These interventions have shown promising results on several health-related and psychosocial dimensions, including reductions in distress, depression, anxiety, and fatigue, and through improvements in quality of life, sleep quality, posttraumatic growth, and mindfulness (e.g. [16, 17]; see [10, 11, 18-20] for reviews). A recent metaanalysis of 29 randomized clinical trials found small to medium size effects of MBIs on psychological distress, depression, anxiety, fatigue, sleep disturbances, fear of cancer recurrence and pain, both after post-intervention and at follow-up [10]. 
MBIs are usually conducted in a face-to-face mode. However, this presents difficulties and challenges, as face-to-face activities are not accessible to all cancer patients and survivors. Barriers to in-person participation in MBIs include living long distances from the health care facility, limited transportation or time, greater burden of the disease and/or cancer treatment (including pain and fatigue), some degree of disability and full family and work schedules [21-24].

The limitations of conducting a face-to-face intervention can be overcome by the internet- or applicationbased psychological activities [25-29]. These approaches have several advantages, including easier management of the specific needs of cancer patients, survivors, and caregivers; easier integration of practices into personal daily routines; reduction of costs for both patients and institutions; and expansion of the accessibility of psychosocial interventions to more people $[21,22,30-34]$. The great relevance of digital technologies has been highlighted in the current COVID-19 pandemic [33], as they play a central role in bringing together health care professionals and patients [35]. This is particularly important in more vulnerable groups, such as cancer patients and survivors [36, 37]. Overall, digital health interventions now present a unique opportunity to consolidate and strengthen psychological interventions, improve the response of health care providers in terms of individual needs, and reduce financial and human resources constraints.

However, the benefits of implementing MBIs using Internet-based tools are unclear [25]. In the specific case of online MBIs, including both healthy and clinical groups, the literature shows positive effects on depression, anxiety, well-being, and mindfulness skills [38, 39]. In relation to cancer patients, several studies suggest that technology-mediated MBIs are feasible and beneficial in improving various psychosocial and health-related outcomes [14]. These include psychological distress, stress symptoms, fatigue, anxiety, depression, mood disturbances, sleep quality, quality of life, spirituality, mindfulness skills, fear of cancer recurrence, and rumination [21, 33, 40-51]. Moreover, greater improvements in anxiety, depression, and posttraumatic growth [14] were reported for online MBIs (compared to control conditions). However, there are other reports of lack of improvement in some of these outcomes, including perceived stress $[48,52]$, depression, anxiety, fatigue $[44,45$, 53], posttraumatic growth [49], rumination [48], physical health-related quality of life [21, 42, 44], pain, spirituality, mindfulness skills $[45,48,53]$, and sleep-related measures $[45,52]$. Thus, the literature information on conducting MBIs with internet-based instruments in cancer care is inconclusive. This may be due to the use of different methods in the reported studies (e.g. type and characteristics of the intervention; mode of delivery; selected outcomes; timing of assessment), and the high variability of sociodemographic and clinical characteristics of the observed groups $[14,48,52]$. This also shows that systematic studies targeting Internet-based MBIs are needed to understand how this valuable tool can be used to benefit all, especially in times of pandemic.

To date, few randomized controlled trials (RCTs) have been published for online MBIs in cancer care [14] and only a small part of these assessed the stability and progression of improvements over time [42, 52, 54]. A subset of these studies showed improvements in psychological distress, anxiety, rumination, and quality of life after intervention [42, 52, 54], while other studies reported no gains in depression [52], fear of cancer recurrence, and physical-related quality of life [42]. This conflicting data may be justified by the use of different self-reported psychosocial and physical outcomes to monitor the effectiveness of online MBIs.

In this regard, beneficial online MBIs should also have a positive effect on biochemical markers, as has been demonstrated with face-to-face interventions [55-58], which could help to extend the benefits of the procedure beyond self-report, and monitor the extent of those benefits. Previously reported data support that face-to-face MBIs modulate immune function [59], contribute to increased telomerase activity [60], and preserve telomere length [61]. These interventions also appear to reduce pro-inflammatory gene expression and inflammatory signalling, as well as salivary cortisol levels [17]. Reductions in pro-inflammatory cytokines, such as interleukin-6 (IL6), tumour necrosis factor-alpha (TNF- $\alpha$ ), and interferon gamma (IFN- $\gamma)[62,63]$ along with increases in antiinflammatory cytokines including IL-4, were also reported [62], supporting that MBIs may help balance immune system activity [55, 57]. In another example involving individuals with prostate cancer, a combination of MBSR with diet affected prostate-specific antigen (PSA) levels [64]. Many other biochemical markers would be of relevance to this topic, but there is not a set of biomarkers that have been selected as preferential for this kind of study [58].

Research work on intercellular communication and signalling through extracellular vesicles (EVs) and their contents (e.g. DNA; mRNAs; microRNAs; proteins; lipids) is rapidly increasing. EVs are cell messengers of health, disease, and stress that circulate through body fluids, and contain important information about the current state of an organism [65-69]. Thus, EVs are now considered a promising tool for signalling a wide variety of biological events.

In addition, EVs are already used in cancer screening, diagnosis, and progression, regardless of the organ from which the EVs originate [70, 71]. It has been shown that 
the secretion of EVs by malignant cells is higher than that of non-malignant ones and that their content also differs in terms of nucleic acid and proteins [72, 73]. Moreover, EVs of malignant cells can influence their neighbouring cells and establish and develop a tumour microenvironment that promotes cancer growth, invasion, and metastasis [70, 71]. Overall, cell-to-cell communication through these vesicles plays a role in the biochemical processes associated with cancer progression and metastasis [70-73], opening an opportunity of investigating biomarker candidates with clinical relevance and developing innovative therapeutic targets in cancer [70, 71, 73].

Specifically, central nervous system (CNS) EVs are viewed with great enthusiasm, because they contribute to better understanding of brain functioning, improve therapeutic management of neurodegenerative and neuropsychiatric clinical conditions [66, 67, 74-76], and may help clarify mind-body interactions that remain unclear despite major advances in science and technology. Moreover, EVs cross the blood-brain barrier, implying that circulating CNS-EVs may contain valuable information about how mind activities may impact the body.

As far as we know, no study has yet addressed the impact of psychological interventions such as MBIs on circulating EVs. It is not known whether they are altered by such interventions, which is not surprising given that EV research is in its infancy. There are also technical challenges involved in isolating CNS-derived EVs, from biofluids such as plasma [71, 73, 74, 76], which are currently being addressed by the project MindGAP (funded by the European Commission).

Therefore, the primary aim of this study is to observe the effect of an internet-based MBCT intervention ( $v s$. treatment as usual) on CNS-EV cargo (objective measure) and psychological distress (subjective measure), in a sample of distressed people with a history of breast, prostate, and colorectal cancer.

A secondary objective is to monitor the direct impact of online MBCT on the overall immunological response (objective measure). For this purpose, several biochemical markers in the blood will be evaluated, including the inflammatory response of interleukins IL-1, IL-6, IL-8, IL-10, IFN- $\gamma$, and TNF, and C-reactive protein. Other biomarkers that are related to cancer recovery after disease termination are also evaluated, including telomerase activity, antigens related to cancer (cancer antigen-CA 15-3; prostate-specific antigen-PSA; carcinoembryonic antigen-CEA), and other health-related markers (adrenocorticotropic hormone; erythrocytes; glycosylated haemoglobin). While biomarkers of cancer recovery are routinely monitored in recovered patients, biomarkers of immunological response are intended to provide a more general picture of the impact of MBCT upon the overall immunological response. This is important to generate relevant data to support any scientific conclusion about the mind-body interaction.

Similarly, secondary subjective psychosocial parameters are also considered, namely quality of life, fear of cancer recurrence, emotion suppression, mindfulness abilities, sleep quality, posttraumatic growth, healthrelated behaviours (physical activity; nicotine dependence), and perceived social support. Care was taken to select brief measures, to minimize participant burden.

To evaluate these global objectives, a one-site two-arm parallel randomized controlled superiority study with a 1:1 allocation ratio to internet-supported MBCR vs. TAU will be conducted, with outcomes measured at five distinct time points: (1) baseline; (2) 4 weeks after baseline (mid-point of the intervention, some self-report measures only); (3) 8 weeks after baseline (post-intervention); (4) 24 weeks after baseline; and (5) 52 weeks after baseline. The last two time points will provide evidence for evaluating the long-term effects of online MBCT.

\section{Methods}

The Standard Protocol Items: Recommendations for Intervention Trials (SPIRIT) 2013 checklist that supports this study can be consulted in Additional file 1 .

\section{Study setting}

The study is conducted at the Instituto Português de Oncologia do Porto (IPOP; Portuguese Oncology Institute of Porto), a reference hospital for cancer in northern Portugal. Data are being collected from Portuguese patients of this hospital. Public data about this trial can be obtained on the website of the project funding this study [77]. The majority of the interactions with participants are being conducted via internet-based platforms.

\section{Participants \\ Eligibility}

The inclusion criteria are summarized in Table 1. It is noteworthy that breast, prostate, and colorectal cancer diseases were selected, as they are the most common cancers in Portugal, with both sexes included [78]. Completion of primary treatments was also considered to minimize the impact of cancer treatment on biological markers, also considering that psychological distress may still be present in people who have had cancer, regardless of survival stage (at least up to 5 years) [79].

In addition, participants must have significant distress at the time of inclusion, defined by a score of 4 or higher on the National Comprehensive Cancer Network (NCCN) Distress thermometer [8], as used in previous MBI studies [23], and considering that this cut-off score indicates moderate distress related to cancer [80, 81]. 
Table 1 Eligibility criteria

\begin{tabular}{|c|c|}
\hline Inclusion & Exclusion \\
\hline $\begin{array}{l}\text { - Age between } 18 \text { and } 65 \text { years old* } \\
\text { - Diagnosis of breast, prostate, or colorectal cancer (cancer stage I to III) } \\
\text { - Primary cancer treatments completed between } 3 \text { months to } 5 \text { years previously } \\
\text { (ongoing hormonal therapy will be included) } \\
\text { - Experience of significant distress at the time of inclusion (DT } \geq 4 \text { ) } \\
\text { - Willingness to accept randomization to one of the two study conditions and } \\
\text { participation in the intervention and data collection for the duration of the } \\
\text { study } \\
\text { - Ability to speak, read, and write in Portuguese and literacy to autonomously } \\
\text { complete the self-report measure } \\
\text { - Sufficient digital literacy and access to a device (e.g. smartphone; tablet; } \\
\text { computer) with a camera, microphone, and internet }\end{array}$ & $\begin{array}{l}\text { - Concurrent diagnosis of severe psychiatric condition(s) (e.g. } \\
\text { bipolar disorder; psychosis; substance abuse; suicidal ideation) } \\
\text { - Concurrent diagnosis of autoimmune disorder } \\
\text { - Current use of antipsychotics } \\
\text { - Current use of anti-inflammatory medication (e.g. corticotherapy) } \\
\text { - Ongoing trastuzumab therapy } \\
\text { - Participation in a structured mindfulness programme (e.g. MBCR; } \\
\text { MBCT; MBSR) in the past } 5 \text { years } \\
\text { - Currently attending psychological consultation } \\
\text { - Being pregnant or breastfeeding }\end{array}$ \\
\hline
\end{tabular}

Note. DT distress thermometer, $M B C R$ mindfulness-based cancer recovery, MBCT mindfulness-based cognitive therapy, MBSR mindfulness-based stress reduction. *This age criterion was considered due to other study of the MindGAP project in which healthy blood donors reporting low psychological distress will be compared with distressed participants diagnosed with cancer for a better characterization of the CNS-EVs. This characterization is important given that CNS-EVs are a novel approach in both healthy and clinical groups. As blood donors are aged between 18 and 65 years, the same criterion was applied to the participants diagnosed with cancer to have a closer age match between groups

\section{Recruitment}

Two main strategies are planned to reach the target population. The first is based on obtaining a list of potential participants from the hospital's Research Outcome Laboratory, filtered by relevant criteria, such as type of cancer and treatments. These potential participants will receive an informative email and/or SMS inviting them to visit the official website of the MindGAP project [77]. This website provides participants with more information about the study, including how to register. In the second variant, IPOP's social networking sites (e.g. Facebook; Instagram; Institutional website) will be used to conduct regular dissemination and invite potential participants to visit the MindGAP's website. Additionally, some health professionals working directly with the target groups will inform potential participants that the current study is recruiting and that more information can be obtained via the website.

In any case, participants can request more information by email or phone. Once contacted, participants receive a link to an online eligibility screening survey. This survey consists of an informed consent form and sociodemographic and health-related questions. If eligibility criteria are met, participants are invited to proceed in the study and to complete the baseline assessment. If any risk is identified (e.g. suicidal ideation), participants are informed about how to access specialist care services.

\section{Informed consent}

Informed consent is obtained directly from potential participants, via the online survey mentioned earlier. Specifically, participants are asked to confirm that they have read the information provided and are willing to collaborate, by checking a box. They will also be asked to authorize the research team to contact them regarding this study, access individual clinical records, and record the intervention sessions. Alternatively, participants will have the option to check a box to end their collaboration.

\section{Sample size estimation}

Because no previous study has examined circulating EVs in relation to MBIs and cancer, we could not use a specific effect size in estimating the sample size. Nonetheless, a recent systematic review examining the effects of Internet-based MBIs on psychological distress (anxiety and depression) found a median Cohen's $d$ value between 0.38 and 0.42 for the other primary outcome, psychological distress [14]. By using $G^{*}$ Power-3.1 statistical software [82] and considering repeated-measures ANOVA related to within-between interaction (group $x$ time interaction), with an alpha significance level of 0.05 and an effect size of 0.38 (as calculated in [83]), a sample of 84 participants would allow for a power of 0.80 . Additionally, previous studies showed dropout rates ranging from 12.1 to $32 \%$ for the intervention group and from 6 and $17.4 \%$ for the control group, when considering the period immediately following the intervention [23, 32, 40, 47, 49, 52, 84]. At follow-up, dropout rates were about $30.8 \%$ in the intervention group and $19.6 \%$ in the control group [52]. Considering the highest dropout rate (32\%), 27 participants should be added to the estimated sample, resulting in a minimum of 111 participants to be included in the study.

\section{Intervention procedures}

A schematic representation of the study design from recruitment to the final follow-up time point is provided in Fig. 1. Briefly, after enrolling in the study, participants must complete the baseline survey, which consists of both biological and self-assessments. It is worthy to note that the self-reported measures are being completed via online surveys, while the biomarkers require the participants to visit the hospital for a blood sample collection. The blood samples will be preferably collected during 


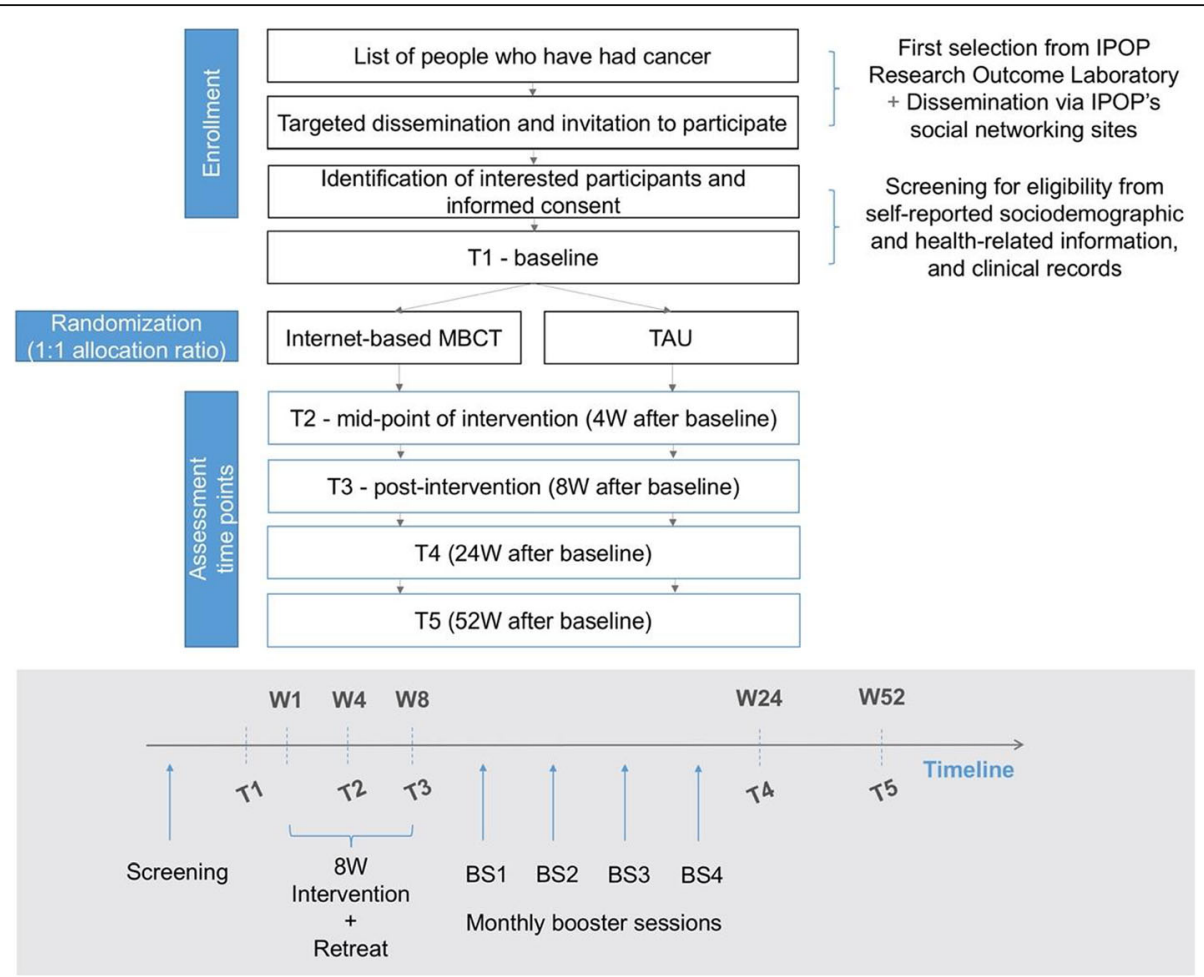

Fig. 1 Study design and participant flow diagram (BS: booster session; IPOP: Instituto Português de Oncologia do Porto; MBCT: mindfulness-based cognitive therapy; TAU: treatment as usual; W: week)

routine clinic visits that occur in all recovered patients. After completing the baseline, participants will be randomized to one of the study conditions, internet-based MBCT or TAU. Subsequent study time points are at 4, 8,24 , and 52 weeks after baseline.

\section{Experimental group}

The MBCT programme [85] is a manualized groupbased training programme that combines aspects of cognitive-behavioural therapy and aspects of the MBSR programme [86]. It was originally developed to reduce the risk of relapse and recurrence associated with major depression, but has also been used for other clinical conditions (e.g. cancer; chronic pain; vascular disease) with satisfactory results (see [87] for an overview). We selected this programme as it has been used in cancer patients with moderate to high levels of distress and has also shown promising results in an online setting [31, $41,42,84,88,89]$.

During the programme, participants learn mindfulness skills to bring attention to the present moment and foster increasing awareness of body sensations, thoughts, and feelings. This includes recognizing and accepting negative and unwanted thoughts, as well as the transitory quality of feelings. The idea is to allow the mind to move from automatic and spiralling patterns to a more conscious processing of mental and physical activities
[90]. Overall, the awareness of the usual patterns of the self shall help to manage and accept unwanted thoughts and feelings.

The online MBCT programme that is being used in this study will be as close as possible to a face-to-face version. It consists of eight weekly 2 -h sessions in a group setting (usually 12 participants), follow-up sessions, and an online retreat that addresses meditation skills and is led by a mindfulness facilitator $[15,85]$. The general structure of the MBCT programme is as follows: the first four sessions are devoted to promoting basic mindfulness skills and psychoeducation regarding unhelpful thoughts; the last four sessions promote an accepting attitude towards unhelpful thoughts and feelings. Each session usually begins with mindfulness and meditation exercises, followed by group discussion, a review of homework activities, and the introduction to new exercises. A summary of the programme can be found in Table 2.

Synchronous sessions and interactions will be conducted via videoconference with the facilitator and other group members (maximum of 12 participants). In addition to the online sessions, participants will be encouraged to complete daily asynchronous homework assignments using support materials created and provided by the programme. For this purpose, participants will be provided with audio-guided exercises shared via an 
Table 2 Overview of the activities planned for the 8-week online MBCT group

\begin{tabular}{|c|c|}
\hline Sessions (general theme) & Synchronous class activities \\
\hline $\begin{array}{l}\text { Session } 1 \text { (recognition of the tendency to be on } \\
\text { automatic pilot) }\end{array}$ & $\begin{array}{l}\text { Establishing and reviewing ground rules } \\
\text { Getting to know the group } \\
\text { Mindfulness meditation exercises: eating a raisin mindfully; } \\
\text { body scan; short breathing focus for } 2-3 \text { min }\end{array}$ \\
\hline $\begin{array}{l}\text { Session } 2 \text { (promotion of awareness of how the } \\
\text { mind responds to daily events and } \\
\text { intensification of body focus) }\end{array}$ & $\begin{array}{l}\text { Mindfulness meditation exercises: body scan; sitting } \\
\text { meditation } \\
\text { Identification of thoughts, feelings, and body reactions in } \\
\text { response to a given daily event }\end{array}$ \\
\hline
\end{tabular}

Session 3 (introduction to breathing space as a way to focus on the present moment when dealing with the busy mind)

Session 4 (reinforcement of mindfulness as a way to stay in the present moment)

Session 5 (promotion of a non-judgmental, open, and receptive attitude toward experience)

Session 6 (unpleasant thoughts and feelings do not represent reality)
Mindfulness meditation exercises: sitting meditation; 3-min breathing space; mindful movement

Calendar with unpleasant events
Mindfulness meditation exercises: sitting meditation; 3-min breathing space; mindful walking

Completion of automatic thoughts questionnaire

Discussion about MBCT based on a video material

Mindfulness meditation exercises: sitting meditation;

breathing space

Preparation of the response plan when dealing with unwanted thoughts and feelings

Mindfulness meditation exercises: sitting meditation; 3-min breathing space
Asynchronous homework activities

Body scan (audio-guided)

Being mindful during a routine

activity

Mindful eating

Body scan (audio-guided)

Mindful breathing

Pleasant events calendar

Being mindful during a different

routine activity

Mindful yoga (audio-guided)

Stretch and breath exercises (audio-

guided)

Unpleasant events calendar

3-min breathing space

Exercise on thoughts, feelings, and considering different perspectives

Discussion of breathing space as way to focus on the present before delving into a wider perspective on thoughts, feelings, and occurring events

Mindfulness meditation exercises: sitting meditation; 3-min breathing space; mindful walking

Investigate associations between activity and mood

Have a list of pleasant activities and how to schedule them

Continue to work on the response plan in pairs and then extend it to the group

Mindfulness mediation exercises: body scan and concluding meditation

Continue to work on the response plan and detection of early warning signs

Review and personal reflections regarding the programme (feedback questionnaire)

Discussion on how to keep daily practices
Sitting meditation (audio-guided) Mindful yoga (audio-guided) 3-min breathing space 3-min breathing after acknowledging the appearance of unwelcome feelings and thoughts

Sitting meditation (audio-guided) 3-min breathing space

3-min breathing after acknowledging the appearance of unhelpful feelings and thoughts

Combination of previous audio-

3-min breathing space

3-min breathing after acknowledging the appearance of unhelpful feelings and thoughts

Continue to work on the response plan

From the practiced exercises, generate a plan of practice to be incorporated into daily routines 3-min breathing space

3-min breathing after acknowledging the appearance of unhelpful feelings and thoughts Continue to work on the response plan

Keep on practicing guided exercises online file hosting service and mp3 players. Participants will be expected to complete daily practices of $10-40$ min six times per week. Home practice will be monitored weekly using online surveys. A 4-h online retreat is proposed after the fifth week of intervention, and 4 monthly booster and consolidation sessions of $2 \mathrm{~h}$ are scheduled after the synchronous sessions.

The mindfulness instructor(s) responsible for the intervention will be mental health professionals with training and clinical experience in $\mathrm{MBCT}$ and following
UK good practice guidelines from the mindfulness-based teacher trainer network [91]. A random pool of sessions from different phases of the programme will be transcribed and compared to the original protocol to assess the level of adherence to the intervention protocol by the therapist(s). For this purpose, sessions will be recorded with the consent of the participants and the mindfulness instructor(s). These recordings can be used to support supervision or intervention by the mindfulness instructor(s) [13]. 


\section{Treatment as usual (TAU)}

Participants in TAU group will follow the routine intervention protocol established by the hospital for needs assessment, referral, follow-up, and management of individuals with significant distress difficulties. Participants will be monitored for recurrence of cancer or other health problems, changes related with pharmacological and non-pharmacological interventions, and the occurrence of other major life events.

\section{Criteria for discontinuing intervention}

In the group receiving $\mathrm{MBCT}$, along with the weekly daily practice survey, participants will be asked to rate their participation in the programme, from harmful to helpful. This will allow monitoring, identifying, and preventing unwanted effects associated to the intervention. If a negative effect is identified, the difficulties will be explored and could result in the intervention being discontinued for those participants. In addition, all participants have the right to terminate their participation at any time. Whenever possible, information about the main reason(s) for dropping out will be requested and recorded.

\section{Adherence and feasibility}

Implementing strategies to promote adherence and prevent dropout is of paramount importance, especially considering dropout rates ranging from 12.1 to $32 \%$ in intervention groups $[23,32,40,47,49,52,84]$ and variability in adherence in online programmes ranging from 52 to $83 \%$ [14]. Such strategies are also relevant when considering adherence in daily practice. Although current data are heterogeneous regarding the frequency and timing of home practice in online MBIs [14], MBIs are estimated to have an adherence rate of approximately $60 \%$ [92, 93]. In addition, studies reported that participants completed between 2 to 4 home exercises per week for online MBIs [46, 94]. Other studies documented reasons underlying for dropping out of online MBIs [21, 40, 52], including technical problems, insufficient technology-related skills, perceived high intensity of the programme, time commitment, lack of motivation, and cancer recurrence or other physical problems.

To avoid technological issues, efforts will be made to provide participants with information on how to complete the online surveys; what is required and how to participate in the videoconference sessions; steps to request specific assistance; in addition to answers to other questions that arise during the study that will be compiled and delivered to participants. Written instructions with step-by-step help information and links to online tutorials will be provided. In addition, interested participants may test the videoconference programme, equipment, and internet in a short session prior to the start of the intervention programme.

Issues such as the intensity and time commitment required by the programme and the compatibility of the programme with daily activities have been identified in the literature as significant barriers to participation [24, 34]. Therefore, flexibility in daily practice is expected. Previous findings suggested that participants prefer short, 10-min mindfulness meditations and more frequently employ body scan exercises, followed by formal sitting meditations, loving-kindness meditations, mindful yoga, and silent meditations [47]. This highlights the need to adapt home practice to a daily routine and offer different exercises with varying lengths to easily accommodate individual preferences [44, 47, 51].

Motivation during the programme is supported and intensified in synchronous group sessions led by instructors, as interpersonal interactions and peer group support have been identified as relevant aspects in online MBIs [21, 31, 34, 53]. Previous studies indicated that participants need to receive reminders about daily training [44]. MBIs that include reminders have been shown to be more likely to have greater effects on outcome measures than MBIs without reminders [28]. Reminders may also lead to better completion rates [95]. However, there is a lack of evidence in the literature about how often these reminders should be given to promote engagement and not an opposite effect (see [14] for a discussion). In this study, we will adopt some of the strategies reported in previous studies, including twiceweekly email reminders [47], reinforced reminders during the synchronous sessions [96], and additional reminders to unresponsive participants [22, 23]. In addition to these interventions, four booster sessions will be implemented to avoid the feelings of disengagement that participants may experience after weekly sessions [97].

The following feasibility measures are considered: recruitment rates (e.g. the proportion of individuals who responded with interest to our invitation; the proportion of individuals who agreed to participate in the study, regardless of eligibility; the proportion of individuals who completed the first assessment point-T1-and began the intervention); adherence to practice (e.g. number of attended sessions; the number of homework assignments completed per week; the average time spent practicing at home each day); programme completion and dropout rates; and programme satisfaction.

Programme satisfaction will be monitored through several approaches: (1) at the third data collection point, participants will receive an online written semistructured questionnaire; (2) mindfulness instructor(s) will be invited to participate in a focus group with the research team; (3) a subset of participants will be invited 
to complete an online adaptation of the Client Change Interview (CCI; [98]; European Portuguese adaptation by [99]). The CCI qualitatively assesses how participants experienced the intervention, perceived changes during the intervention, what these changes are due to, positive and negative aspects related to the intervention, and suggestions. In this interview, participants use three 5-point Likert-type scales to rate: expected change (1-very much expected; 5-very much surprised by it); change without intervention (1-clearly would not have happened; 5-clearly would have happened anyway); the value of the change (1-not at all important; $5-$ extremely important).

\section{Outcome measures}

The primary and secondary outcomes collected via selfreport measures are briefly described and summarized in Table 3. In short, primary outcomes are CNS-EV cargo (objective measure) and psychological distress (self-report measure). Secondary outcomes include selfreported psychosocial and health-related measures (quality of life; fear of cancer recurrence; emotion suppression; mindfulness abilities; sleep quality; posttraumatic growth; health-related behaviours; perceived social support) and a variety of biomarkers (IL-1; IL-6; IL-8; IL-10; IFN- $\gamma$; TNF; C-reactive protein; CA 15-3; PSA; CEA; adrenocorticotropic hormone; erythrocytes; glycosylated haemoglobin).

The timing of these measures is shown in Table 4. All psychosocial measures employed at baseline (T1) are used at T3, T4, and T5. In the fourth week after the baseline (the fourth session in the case of the intervention group), self-reported measures of distress and mindfulness will be used. This intermediate point (T2) was considered as previous studies have suggested that four sessions are the minimum satisfactory intervention dose $[14,52,84,89]$. Few measures were selected at T2 to avoid participant burden. Regarding biological samples, the plans are to collect them at T1, T3, and T4. Of note, participants will receive financial compensation for the costs they incur traveling to IPOP to participate in the blood collections.

For each self-report measure, the total score obtained for scale and/or subscales will be used as outcomes. Measures examining the eligibility criteria and the sociodemographic and health-related information are also reported in Table 3.

To determine EVs cargo, total EVs will be isolated from platelet-free plasma samples by ultracentrifugation, followed by a purification step for CNS-derived EVs by immunoprecipitation with CNS-specific antibodies. Since we are interested in CNS-derived EVs, brainrelated microRNAs will be measured to verify the origin of the EVs. This is achieved by isothermal nucleic acid amplification method. Results are measured by luminescence.

To evaluate the biochemical markers, inflammatory response biomarkers (IL-1, IL-6, IL-8, IL-10, IFN- $\gamma$, TNF) will be detected in serum by multiplex immunoassay (MILLIPLEX ${ }^{\circ}$ Multiplex Assays Using Luminex ${ }^{\circ}$ ). Similarly, various cancer antigens (CA 15-3 and CA 19.9 in units/mL, PSA in $n g / m L$, CEA in $n g / m L$ ) will also be detected by immunoassay to monitor cancer recurrence. Other health-related biomarkers will include c-reactive protein $(\mathrm{mg} / \mathrm{L})$, telomerase activity, erythrocyte number (million/ $\left./ \mathrm{mm}^{3}\right)$, adrenocorticotropic hormone $(\mathrm{pg} / \mathrm{mL}$ via immunoassay analyser), and glycosylated haemoglobin $(\mathrm{mmol} / \mathrm{mol}$ via high-performance liquid chromatography).

\section{Assignment of intervention \\ Allocation}

Participants will be randomly assigned to one of the two arms: MBCT or TAU groups (1:1 allocation ratio). Randomization blocks will be created using informatic tools and the entire process will be overseen by an investigator who will not be directly involved in the intervention or assessments. This investigator will inform the research team of the final allocation of each participant.

\section{Blinding}

Prior to randomization, individuals involved in the study (participants, study coordinators, mindfulness instructor(s), research assistants, statistician) will be blinded to the study conditions. After randomization, the research team will inform participants about group membership. Similar to previous studies in the field [14], and given the specificities and resources available in the current study, it is impossible to guarantee further blinding of participants and staff irrespective of their role. This unblinding also applies to the data analysts as most of the team members involved in the data collection will participate in the data management and analysis. Even so, the team members not collaborating directly in the data collection, such as the team dedicated to the characterization of the CNS-derived EVs, will be blinded to the study conditions where possible.

\section{Data collection and management}

After registration, participants will be assigned randomly generated identification codes. They will be asked to keep and use the code to avoid inserting sensitive personal data during their participation. Correspondence between the code and participant's personal information (e.g. name; contact information; clinical identification in IPOP) is stored in a metadata file that is encrypted with a password and accessible only through the IPOP's 
Table 3 Summary of self-report primary and secondary outcomes, respective assessment measures, and screening measures

\begin{tabular}{|c|c|c|}
\hline Outcome & Measure & Brief description \\
\hline \multicolumn{3}{|l|}{ Primary } \\
\hline Psychological distress & $\begin{array}{l}\text { Depression Anxiety Stress Scales-21 (DASS-21 } \\
\text { [100]; EP version by [101]) }\end{array}$ & $\begin{array}{l}\text { It is a public domain instrument that evaluates negative affective states, } \\
\text { being one of the available measures to assess psychological distress } \\
{[102,103] \text {. It is also used in RCTs of manualized MBIs in the oncological }} \\
\text { context [104]. It is an abbreviated version of the original version of } 42 \\
\text { items and can be administered to people aged } 18 \text { or more. It comprises } \\
21 \text { items, } 7 \text { measuring depression, } 7 \text { measuring anxiety, and } 7 \\
\text { measuring stress. Specifically, participants are required to rate each item } \\
\text { on a 4-point Likert-type scale as reference to how they have been feel- } \\
\text { ing during the last week. The rating scale varied between } 0 \text { and 3, in } \\
\text { which } 0 \text { represents "did not apply to me at all" and } 3 \text { represents "ap- } \\
\text { plied to me very much or most of the time". The score for each subscale } \\
\text { is obtained by summing the respective } 7 \text { items, whose result range be- } \\
\text { tween } 0 \text { and } 21 . \text { In this study, a total score will be used by summing all } \\
\text { items, with higher scores being indicative of higher self-reported nega- } \\
\text { tive affective experiences. The EP version yielded satisfactory internal } \\
\text { consistency and convergent and discriminant validity [101]). }\end{array}$ \\
\hline
\end{tabular}

Secondary

Emotion suppression

Fear of cancer recurrence

Mindfulness

Nicotine dependence
Expressive Suppression scale of the Emotion Regulation Questionnaire (ERQ [105]; EP version by [106])

7-item Fear of Cancer Recurrence Questionnaire (FCR7 [109])

Five-Facet Mindfulness Questionnaire (FFMQ $[111,112]$; EP version by [113])
It evaluates strategies of emotional regulation, particularly cognitive reappraisal, and expressive suppression. It is a brief questionnaire including 10 items, 4 dedicated to expressive suppression and 6 to cognitive reappraisal, contributing to the 2 -factor structure. Each item is rated on a 7-point Likert-type scale, wherein 1 represents strongly disagree and 7 strongly agree. Two scores are derived, one related to cognitive reappraisal (ranging from 6 to 42 ) and the other related to expressive suppression (ranging from 4 to 28). Higher scores indicate higher employment of the regulation strategy under evaluation. The original study demonstrated that ERQ has good psychometric properties of internal consistency, test-retest reliability, convergent, and discriminant validity. These good properties have been replicated in different samples such as community samples (e.g. [107]) and people diagnosed with cancer, including in the Portuguese context (e.g. [108]). In the current study, only the expressive suppression scale will be used as an outcome.

It is a unidimensional screening measure of FCR to be used in oncological contexts. It is composed of 7 items, most of them rated in a 5-point Likert-type scale ranging from 1 (not at all) to 5 (all the time) and one item rated in a 10-point scale ranging from 0 (not at all) to 10 (a great deal). Higher scores are indicative of higher reported levels of FCR. As a reference, a score of 17 corresponds to a moderate level of FCR and a score of 27 corresponds to a high level. Satisfactory psychometric properties have been documented in terms of internal consistency, test-retest reliability (1-month), content and convergent validity [110]. As FCR7 is a recent questionnaire, no EP version is yet available. Thus, the research version is being developed in the context of this study.

It was developed based on a comprehensive analysis of different mindfulness questionnaires, supporting the notion that mindfulness is a multifaceted construct. Specifically, this questionnaire assesses mindfulness and self-awareness states in everyday life, incorporating five facets/subscales: observing, describing, acting with awareness, nonreactivity to inner experience, and nonjudging of inner experience. It encompasses 39 items, each one rated on a 5-point Likert-type scale ranging from 1 (never or very rarely true) and 5 (very often or always true). A score is derived for each facet. This questionnaire has been widely used in intervention studies. In addition, it has been adapted to different cultures with good results [114]. In the case of the EP version, satisfactory psychometric properties for the five-dimension solution in terms of internal consistency, convergent and discriminant validity had been reported [113].

Fagerström Test for Nicotine Dependence (FTND [115]; EP version by [116])
It is a widely used questionnaire to assess nicotine dependence. It is a brief measure composed of 6 items. Two of the items are scored between 0 and 3, and the remaining are scored between 0 and 1. Thus, the total score ranges between 0 and 10. The EP version has been tested for internal consistency and test-retest reliability with satisfactory 
Table 3 Summary of self-report primary and secondary outcomes, respective assessment measures, and screening measures (Continued)

Outcome Measure Brief description

results. Also, a two-factor structure emerged, one related to cigarette consumption and the other related to morning smoking [116]. Of note, to complement the data regarding the consumption of substances that may interfere with the biological markers under study, questions concerning the weekly consumption of alcohol, coffee, coffee-based beverages, and tea, as well as the type of diet and its selfperceived quality will be added.

Physical activity

International Physical Activity Questionnaire Short Form (IPAQ - SF; [117])

Posttraumatic growth

Quality of life

Sleep quality
Posttraumatic Growth Inventory (PTGl [119]; EP version by [120])

World Health Organization Quality of Life - Bref (WHOQOL-Bref [122, 123]; EP version by [124])

Basic Scale on Insomnia complaints and Quality of Sleep (BaSIQS [127])
It evaluates physical activity and sedentary behaviour (sitting). In this study, the short form will be used because it is faster and easier to administer while maintaining similar reliability and validity properties as compared to the extended version. It contains 9 items encompassing the frequency (days) and time spent on walking, moderate-intensity activities, vigorous-intensity activities, and sedentary activities. The reference period to be used in the current study will be the "usual week". An estimation of time (minutes) per week dedicated to each type of intensity (vigorous, moderate, walking) and sitting can be obtained. From these data it is possible to estimate the total weekly physical activity in MET minutes per week. Also, it is possible to categorize the people into 3 possible levels of physical activity: low, moderate, or high (the following protocol can be used: https://sites.google.com/site/theipaq/scoringprotocol). Concerning the psychometric properties, acceptable results were described in the study of Craig and collaborators [117], considering test-retest reliability (around 1 week), criterion (based on accelerometer), and concurrent (based on short and long versions) validity. Although scarce, the evidence available for the EP adaption is also reasonable [118].

It is a self-report questionnaire that assesses positive psychological change in people that faced traumatic experiences. It is composed of 21 items structured in a 5 -factor model: new possibilities (5 items); relating to others (7 items); personal strength (4 items); spiritual change (2 items); appreciation of life (3 items). Each item is rated on 6-point Likerttype scale ranging from 0 ("I did not experience this change as a result of my crisis") to 5 ("I experienced this change to a very great degree as a result of my crisis"). The total score varies between 0 and 105, with higher scores depicting a greater degree of posttraumatic growth. The original study revealed satisfactory internal consistency, test-retest reliability (2 months), construct, concurrent, and discriminant validity. The Portuguese adaptation including participants diagnosed with breast cancer and non-clinical participants yielded reasonable psychometric properties $[120,121]$.

It is the abbreviated version of the 100-item instrument (WHOQOL-100), suitable for epidemiological and clinical trials, which evaluates the quality of life following the WHO's proposal (i.e. the perception of an individual regarding one's position in life given the cultural and social environment, as well as expectations, preoccupations, and goals). It includes 26 items arranged in one general facet and four specific domains: physical health, psychological, social relationships, and environment. Each item is rated having the last 2 weeks as the time period of reference and using a 5-point Likert-type scale. The scoring procedures can be consulted here: https://www.who.int/mental_health/ media/en/76.pdf. Higher scores indicate higher self-reported quality of life. The original studies showed satisfactory psychometric properties in terms of internal consistency, test-retest reliability, construct, discriminant, and criterion validity. Similarly, satisfactory psychometric properties of validity and reliability were documented for the Portuguese adaptation [124], being successfully used in several studies with Portuguese oncological groups (e.g. $[125,126])$.

It is a brief easy to administer self-report questionnaire that evaluates sleep quality and difficulties related to fall asleep and to maintaining sleep, considering a typical week in the last month. It encompasses 7 items rated on a 5-point Likert-type scale, and each one scored between 0 and 4 . The total score ranges between 0 and 28, with the highest values being indicative of poor sleep quality. This questionnaire was initially developed and tested with groups of Portuguese higher education students, yielding good internal consistency, test-retest reliability, and 
Table 3 Summary of self-report primary and secondary outcomes, respective assessment measures, and screening measures (Continued)

\begin{tabular}{|c|c|c|}
\hline Outcome & Measure & Brief description \\
\hline & & $\begin{array}{l}\text { convergent validity. Normative scores for males and females were pre- } \\
\text { sented based on percentiles, } 25,50 \text {, and } 75 \text {. These good psychometric } \\
\text { properties were also extended to a Portuguese community sample, and } \\
\text { BaSIQS was able to distinguish between people with clinical insomnia } \\
\text { and people with sleep disturbance [128]. } \\
\text { In the current study, additional questions available in the plus version of } \\
\text { BaSIQS will be included, namely the number of hours usually slept per } \\
\text { night during week and weekend, frequency of nights per week wherein } \\
\text { the participant is able to sleep the number of needed hours, frequency } \\
\text { and duration of naps, and perceived subjective sleep problems. }\end{array}$ \\
\hline Social support & Social Support Satisfaction Scale (SSSS [129]) & $\begin{array}{l}\text { It is a self-report questionnaire that assesses perceived social support. It } \\
\text { is composed of } 15 \text { items distributed in four factors: satisfaction with } \\
\text { friendship ( } 5 \text { items), intimacy ( } 4 \text { items), satisfaction with family ( } 3 \text { items), } \\
\text { and social activities ( } 3 \text { items). Each item is rated on a } 5 \text {-point Likert-type } \\
\text { scale, ranging from totally agree to totally disagree, and scored between } \\
1 \text { and } 5 \text {. A score can be obtained for each subscale, but the total score } \\
\text { will be considered in this study. The total score can be extracted by } \\
\text { adding each subscale score, and it ranges between } 15 \text { and } 75 \text {, with } \\
\text { higher scores representing higher perceived social support. The original } \\
\text { study conducted with a Portuguese sample revealed good internal } \\
\text { consistency, discriminant, and concurrent validity. Reasonable psycho- } \\
\text { metric properties of validity and reliability were also reported study with } \\
\text { a Portuguese and Brazilian sample of university students [130]. }\end{array}$ \\
\hline
\end{tabular}

Screening

Distress

Distress thermometer (DT [7])

Global distress and mental health difficulties

Clinical Outcome Routine Evaluation - Outcome Measure (CORE-OM [131-133]; EP version by [134])
It is a simple visual analogue scale with 11 points (from 0-no distress to 10-extreme distress) shaped like a thermometer and devised to screen the experience of distress during the last week in oncology populations. The higher the value selected, the higher the level of distress reported by the participant.

It is a self-report measure that incorporates 34 items organized in four different dimensions: well-being (4 items), symptoms (12 items), social and personal functioning (12 items), and risk behaviours ( 6 items). Each item is evaluated using a 5-point Likert-type scale that varies from 0 (not at all) to 4 (most or all the time). The time window of reference is the last week, and it takes about 5-10 min to complete. The original total score is obtained by averaging all the items. The mean score can be multiplied by 10 to facilitate interpretation, resulting in scores ranging between 0 and 40 . Higher values denote a more severe level of global distress (see https://www.coresystemtrust.org.uk/instruments/ core-om-information/). CORE-OM has been widely tested and demonstrates satisfactory concurrent and convergent validity, internal consistency, and test-retest reliability (1-week interval; [131-133]). Good internal consistency was also found in the EP adaption [134].

It consists in information to be obtained directly from participants or clinical records: age; gender; years of formal education; nationality(ies); mother language(s); marital status; current regional location of residence; professional occupation and current occupational situation; average household income (mensal); children (number and ages); informal care provided to other persons; people living in the household; clinical history; familial cancer history, date and age of the cancer diagnosis, who detected the cancer, type of cancer and site, stage, cancer treatments (including start and end date); comorbidities (e.g. hypertension; diabetes mellitus; autoimmune diseases such as lupus, thyroiditis, rheumatoid arthritis); history of surgical interventions; pharmacological treatments and possible adjustments in the last 3 months; psychological intervention; psychiatric intervention; mindfulness meditative practices; menopause signs and symptoms in the case of female participants.

Note. BaSIQS Basic Scale on Insomnia complaints and Quality of Sleep, CORE-OM Clinical Outcome Routine Evaluation - Outcome Measure, DASS-21 Depression, Anxiety Stress Scales-21, DSM Diagnostic and Statistical Manual, DT distress thermometer, EP European Portuguese, ERQ Emotion Regulation Questionnaire, EVs extracellular vesicles, FCR-7 7-item Fear of Cancer Recurrence, FFMQ Five-Facet Mindfulness Questionnaire, FTND Fagerström Test for Nicotine Dependence, ICD International Classification of Diseases, IPAQ-SF International Physical Activity Questionnaire - Short Form, MBIs mindfulness-based interventions, $n / a$ not applicable, PTGI Posttraumatic Growth Inventory, RCT randomized controlled trial, SSSS Satisfaction with Social Support Scale, WHOQOL-Bref World Health Organization Quality of Life - Bref 
Table 4 Schedule of enrolment, interventions, and assessments

\begin{tabular}{|c|c|c|c|c|c|c|c|c|}
\hline & & & & dy period & & & & \\
\hline & Screening & Baseline & Allocation & $\begin{array}{c}8 \mathrm{~W} \\
\text { treatment }\end{array}$ & $4 \mathrm{~W}$ & $8 \mathrm{~W}$ & $24 \mathrm{~W}$ & $52 \mathrm{~W}$ \\
\hline Timepoint & & T1 & & & $\mathrm{T} 2$ & T3 & $\mathrm{T} 4$ & T5 \\
\hline Enrollment & & & & & & & & \\
\hline Informed consent & $X$ & & & & & & & \\
\hline Eligibility screen & $\mathrm{X}$ & & & & & & & \\
\hline Allocation & & & $X$ & & & & & \\
\hline Interventions & & & & & & & & \\
\hline Online MBCT & & & & $\longleftrightarrow$ & & & & \\
\hline TAU & & & & $\longleftrightarrow$ & & & & \\
\hline Events monitoring & & & & $\longleftrightarrow$ & & & & \\
\hline $\begin{array}{l}\text { Self-report } \\
\text { questionnaires }\end{array}$ & & & & & & & & \\
\hline BaSIQS & & $\mathrm{X}$ & & & & $\mathrm{X}$ & $\mathrm{X}$ & $\mathrm{X}$ \\
\hline $\mathrm{CCI}$ & & & & & & $\mathrm{X}$ & & \\
\hline CORE-OM & $\mathrm{X}$ & & & & $\mathrm{X}$ & $\mathrm{X}$ & $\mathrm{X}$ & $\mathrm{X}$ \\
\hline DASS-21 & & $\mathrm{X}$ & & & $X$ & $\mathrm{X}$ & $\mathrm{X}$ & $\mathrm{X}$ \\
\hline DT & $X$ & $\mathrm{X}$ & & & & & & \\
\hline ERQ & & $\mathrm{X}$ & & & & $\mathrm{X}$ & $\mathrm{X}$ & $\mathrm{X}$ \\
\hline FCR-7 & & $\mathrm{X}$ & & & & $\mathrm{X}$ & $\mathrm{X}$ & $\mathrm{X}$ \\
\hline FFMQ & & $X$ & & & $X$ & $\mathrm{X}$ & $\mathrm{X}$ & $\mathrm{X}$ \\
\hline FTND & & $\mathrm{X}$ & & & & $\mathrm{X}$ & $\mathrm{X}$ & $\mathrm{X}$ \\
\hline IPAQ-SF & & $\mathrm{X}$ & & & & $\mathrm{X}$ & $X$ & $\mathrm{X}$ \\
\hline PTGI & & $\mathrm{X}$ & & & & $\mathrm{X}$ & $X$ & $\mathrm{X}$ \\
\hline SSSS & & $\mathrm{X}$ & & & & $\mathrm{X}$ & $\mathrm{X}$ & $\mathrm{X}$ \\
\hline
\end{tabular}

Sociodemographic and clinical information WHOQOL-BREF

Biological markers Adrenocorticotropic hormone

CA 15-3

CEA

CRP

Erythrocytes

Hemoglobin

glycosylated

IFN- $\gamma$

IL-1

IL-6

IL-8

IL-10

PSA

Telomerase activity

TNF
X

\begin{tabular}{|c|c|c|c|}
\hline$X$ & $\mathrm{X}$ & $X$ & $\mathrm{X}$ \\
\hline$X$ & $\mathrm{X}$ & $\mathrm{X}$ & \\
\hline$X$ & X & $X$ & \\
\hline $\mathrm{X}$ & $X$ & $\mathrm{X}$ & \\
\hline$X$ & $X$ & $\mathrm{X}$ & \\
\hline $\mathrm{X}$ & $\mathrm{X}$ & $\mathrm{X}$ & \\
\hline$X$ & $X$ & $X$ & \\
\hline$X$ & $X$ & $X$ & \\
\hline $\mathrm{X}$ & $X$ & $\mathrm{X}$ & \\
\hline $\mathrm{X}$ & $X$ & $X$ & \\
\hline$X$ & $X$ & $X$ & \\
\hline $\mathrm{X}$ & $\mathrm{X}$ & $X$ & \\
\hline$X$ & $X$ & $X$ & \\
\hline$X$ & X & $X$ & \\
\hline$X$ & $\mathrm{X}$ & $\mathrm{X}$ & \\
\hline
\end{tabular}

Note. BaSIQS: Basic Scale on Insomnia complaints and Quality of Sleep; CA: Cancer Antigen; CCI: Client

Change Interview; CEA: Carcinoembryonic Antigen; CORE-OM: Clinical Outcome Routine Evaluation -

Outcome Measure; CRP: C-Reactive Protein; DASS-21: Depression, Anxiety Stress Scales-21; DT: Distress

Thermometer; ERQ: Emotion Regulation Questionnaire; FCR-7: 7-item Fear of Cancer Recurrence; FFMQ:

Five Facet Mindfulness Questionnaire; FTND: Fagerström Test for Nicotine Dependence; IFN- $\gamma$ - Interferon

Gamma; IL: Interleukin; IPAQ-SF: International Physical Activity Questionnaire - Short Form; MBCT:

Mindfulness-Based Cognitive Therapy; PSA: Prostate-Specific Antigen; PTGI: Posttraumatic Growth

Inventory; SSSS: Satisfaction with Social Support Scale; TAU: Treatment as Usual; TNF: Tumor Necrosis

Factor; W: Weeks; WHOQOL-Bref: World Health Organization Quality of Life - Bref.

Note. BaSIQS Basic Scale on Insomnia complaints and Quality of Sleep, CA cancer antigen, CCI Client Change Interview, CEA carcinoembryonic antigen, CORE-OM Clinical Outcome Routine Evaluation - Outcome Measure, CRP C-reactive protein, DASS-21 Depression, Anxiety Stress Scales-21, DT distress thermometer, ERQ Emotion Regulation Questionnaire, FCR-7 7-item Fear of Cancer Recurrence, FFMQ Five-Facet Mindfulness Questionnaire, FTND Fagerström Test for Nicotine Dependence, IFN- $\gamma$ interferon gamma, IL interleukin, IPAQ-SF International Physical Activity Questionnaire - Short Form, MBCT mindfulness-based cognitive therapy, PSA prostate-specific antigen, PTGI Posttraumatic Growth Inventory, SSSS Satisfaction with Social Support Scale, TAU treatment as usual, TNF tumour necrosis factor, W weeks, WHOQOL-Bref World Health Organization Quality of Life - Bref 
computer, which is protected by institutional security measures.

Data on sociodemographic and health self-report, screening, and primary and secondary outcome measures will be stored in the online survey service used here, LimeSurvey, which adheres to user privacy policies. Data will be periodically copied to an IPOP computer, where they are processed and inserted into excel files. These files will only be accessible to members of the IPOP research team via passwords or physical keys to open specific doors in the case of paper-based documentation, which will be kept in cabinets and locked.

Biological marker data will be obtained from blood samples collected from participants using a 21- to 23gauge needle into 3 EDTA tubes $(\leq 12 \mathrm{~mL})$ and 1 nonadditive tube $(4 \mathrm{~mL})$. The standard tubes are stored at $4{ }^{\circ} \mathrm{C}$ for a maximum of $180 \mathrm{~min}$. Tubes will be centrifuged at $2500 \mathrm{~g}$ for $30 \mathrm{~min}$ at $4{ }^{\circ} \mathrm{C}$. The upper third of plasma will be transferred to sterilized $2 \mathrm{~mL}$ tubes, and the plasma samples will be aliquoted and stored at $-80^{\circ} \mathrm{C}$ in the hospital biobank until further use. The tubes will be labelled with a reference to the MindGAP project and a participant identification code to ensure anonymization during the blood collection and processing. Prior to EV isolation, a centrifugation step at $5000 \mathrm{~g}$ for $15 \mathrm{~min}$ is performed in thawed plasma samples, to remove most of the remaining platelets.

For both self-reported and biological data, a privacy impact assessment has already been submitted, analysed, and approved by the IPOP's Data Protection Officer.

\section{Statistical methods}

Screening data for errors and missing values is the first step in the data analysis plan. Missing data will be managed and avoided during the data collection by using mandatory fields in the online surveys and retrieving the data from participants when possible. Data from participants who completed fewer than 4-weekly online MBCT sessions will not be considered further, as four sessions were set as the minimum number required for participation [14].

For each group (MBCT and TAU), a summary of baseline sociodemographic and health data will be provided, including number and percentages, mean, standard deviation, median, first and third quartiles, minimum and maximum. Using the sociodemographic and health data, as well as the primary and secondary measures, comparisons will be made between groups to examine whether there are differences between groups at baseline. Similarly, differences at baseline between participants who will complete the study and those who will drop out will be examined. The presence of differences in variables may warrant the need to examine and/or adjust for their influence on outcome changes in the primary analyses. This summary also presents the within-group effect sizes (Cohen's $d$-equation 11.10, from [135]) for each outcome across time (i.e. T1 to T2; T1 to T3; T1 to T4; T1 to T5).

The total scores of each primary and secondary measure will be used as outcomes in multiple linear mixed models (LMMs). Each model will include the interaction between group and time, while participants will be treated as a random effect. The visual inspection of Q-Q plots will be conducted to check the normal distribution of residuals. Examination of factors such as sex, type of cancer, and cancer stage will be approached by running separate models for each factor. LMM analyses can be employed using, for instance, lmer4 [136] and lmerTest [137] in R software [138].

Descriptive statistics for feasibility indicators (see "Adherence and feasibility" section) will be documented. In the case of programme satisfaction, a qualitative analysis of the information collected in the semi-structured interview, focus groups, and CCI will be conducted [98]. For this purpose, a computer-assisted thematic analysis will be used, following Braun and Clarke's 6-step approach [139] (see also [140, 141]): (i) familiarization with the data (transcribing the non-written data to a written format and carefully reading all the material several times to become familiar with it); (ii) initiation of the coding process (identifying emergent units of meaningcodes-that are relevant to the research and can be used to tag similar data); (iii) generation of potential and broader themes (codes can be categorized according to the themes and a thematic map that contains associations between themes, including major and sub-themes, and between codes); (iv) review the themes (themes are reviewed to verify if they fit the coded data so that they can be deleted, modified, merged and/or separated; also, the accuracy of the thematic map is reviewed); (v) description of themes (provide a name, characterization, and a scope, and refine the themes step by step); (vi) report of analysis (write and describe in detail the process of analysis using data supporting the themes and discuss the results in light of the literature and research goals). As recommended, steps 1-3 will be conducted by at least two independent researchers and later brought into the group discussion to promote thematic and code reliability [142].

\section{Oversight and monitoring}

No Data Monitoring Committee was designated given the nature of the study, i.e. psychosocial intervention with low risk. Nonetheless, participants in the intervention group will be monitored weekly for their experience in the intervention sessions. The aim is to detect adverse events associated with the intervention (see [14, 24] for some examples), to discontinue the intervention or, if 
necessary, to make a referral to specialist care services. The IPOP's research team will be responsible for this monitoring process, and any incident will be documented in the participant flow diagram.

This study has no designated coordinating centre or trial steering committee. The IPOP's research team have the responsibility to conduct and monitor the day-byday tasks necessary to run the study. This team meets periodically to assess the conduct and progress of this study and to ensure compliance with the study protocol. There are also meetings every 3 months including the IPOP's team members responsible for the study coordination (ERS, CJ, and RH) to discuss management and financial issues related to the study. The person responsible for the financial management of the study also participates in some of these meetings. Additionally, the study is discussed in the bi-annual consortium meetings of the MindGAP project [77]. This allows to share with the other research partners the current status of the clinical study, achievements and goals, being an opportunity to receive feedback and guidance. Other than these meetings, no formal auditing is planned as the IPOP has no audit department dedicated to this type of study.

Changes to the study protocol will first be submitted to the IPOP Ethics Committee and after approved updated accordingly in clinicaltrials.gov. The updates will also be reported to the MindGAP project research partners during the consortium meetings.

\section{Dissemination plans}

The activities and results of the MindGAP project are updated on the project website [77] and disseminated on the project's social networking platforms (Facebook, Twitter, LinkedIn, YouTube), which are linked on the project homepage. The public can interact with the research team through the former channels. The results of the study will be presented in scientific meetings and published in open-access journals. By the end of this study, it is planned to present the results to participants, healthcare professionals, and the community in an open session organized at IPOP. Social and traditional media platforms could also be used to reach a wider audience.

\section{Discussion}

The motivation of this study is twofold: (1) to test the influence of MBCT practices on circulating CNS-derived EVs, investigated here for the first time; (2) and to further substantiate the impact of Internet-based MBCT on psychosocial and biological markers in an oncological context.

The use of CNS-derived EVs as tool for discovering biomarkers to support the psychosocial and biological changes that occur in the body following MBCT practices is a novel perspective never explored in the literature. The novel hypothesis presented here suggests that EVs may be involved in an important neurobiological mechanism of action underlying mindfulness interventions. Circulating CNS-EVs carry information to peripheral cells, and this information acts as instructions to these cells sent via mind-controlled events. In this hypothesis, EVs could lead to a further understanding of how mind-controlled activities can cause biological changes in the body.

There are challenges and limitations with this study that need to be acknowledged. First, the inclusion of participants with some level of digital literacy and access to digital devices and the Internet likely reflects sociodemographic characteristics, with younger and more educated participants being more mobilized [143]. Access to and use of information and communication technologies in Portugal is still closely associated with age and education, meaning that older and less-educated individuals are not as involved as other sociodemographic groups [144]. Accordingly, the results of this study may not apply to people with other sociodemographic characteristics. Nevertheless, this is an important step towards the development of digital mental healthcare services, whose underdevelopment in Portugal has been exposed by the current pandemic situation [145].

Moreover, despite the inclusion of specific types of cancer, which allows the formation of more homogeneous groups, as recommended in previous literature $[14,57]$, some individual characteristics and needs may be unconsidered. Accordingly, future studies could benefit from investigating other cancer types and stages (in treatment and palliative conditions [79]), exploring new ways to consider individual aspects [146], and including other outcomes (e.g. cognitive dysfunction, fatigue, pain) and possible associations with biological parameters [56].

Furthermore, given the novelty behind this study, the sample size of the objective primary outcome could not be adequately estimated for EV studies. Therefore, the current study may be underpowered to detect the effects of internet-based MBCT on circulating EVs. This problem could be compounded by difficulties with adherence and retention in this study, given the time and other specific demands of mindfulness practice [33]. With this concern in mind, specific strategies to mitigate dropouts were identified. Also, the qualitative methods proposed in this study might be useful in this regard.

The control data is obtained here by following TAU. This control condition was selected considering the available resources, the time window for conducting this clinical study, the previous use in online MBI studies $[46,48,52,53,84,89]$, and the desire for a year of follow-up comparison data (hence precluding a short 
waitlist period for the control group). We are aware that this approach does not allow control of specific (e.g. psychoeducational aspects) and nonspecific effects (e.g. group interactions and support; closer supervision; interaction with mental health professionals) [90]. An active control or even a comparison with another established intervention would be preferable, if possible [13, 90]. However, passive control conditions have been the most common in digital MBI research to date. As the field evolves, active control conditions are likely to become more common, as suggested by studies comparing faceto-face MBIs with Internet-based MBIs [31, 41, 42, 54, 84,89 ] or studies using psychoeducational intervention as a comparison $[32,40]$.

Considering the challenges and limitations discussed earlier, it is important to say that not all scenarios are predictable. Therefore, the possibility of overcoming the challenges by adopting new or adapted strategies that may prevent the difficulties encountered throughout this study is anticipated, in a manner that provides valuable insights into health-related and psychosocial gains fostered by internet-based MBCT in an oncology context.

Overall, it is expected to confirm and clarify the role of CNS-EVs in altering the biochemical operation of peripheral cells in response to mind-related activities, while monitoring the extent of these changes in a wide range of subjective and objective parameters. This mechanism may open unprecedented opportunities to understand how the mind may interact with the body, in what quantitative dimension, and also provide tools for a mind-controlled activity that may benefit health.

\section{Trial status}

The unique protocol ID is IPO/PI134b and the ClinicalTrials.gov Identifier is NCT04727593 (date of registration: 27 January 2021; date of record verification: 6 October 2021; https://clinicaltrials.gov/ct2/show/ NCT04727593). The first wave of recruitment began on February 2021 and it is expected to continue until October 2022. The anticipated study completion date is March 1, 2023.

\section{Abbreviations}

ACTH: Adrenocorticotropic Hormone; BaSIQS: Basic Scale on Insomnia Complaints and Quality of Sleep; CA: Cancer Antigen; CCl: Client Change Interview; COPE: Committee on Publication Ethics; CORE-OM: Clinical Outcome Routine Evaluation - Outcome Measure; CNS: Central Nervous System; CRP: C-Reactive Protein; DASS-21: Depression, Anxiety Stress Scales21; DSM: Diagnostic and Statistical Manual; DT: Distress Thermometer; ERQ: Emotion Regulation Questionnaire; EVs: Extracellular Vesicles; FCR-7: 7item Fear of Cancer Recurrence; FFMQ: Five-Facet Mindfulness Questionnaire; FTND: Fagerström Test for Nicotine Dependence; HPLC: High-Performance Liquid Chromatography; ICD: International Classification of Diseases; IFNү: Interferon Gamma; IFN: Interferon; IL: Interleukin; IPAQ-SF: International Physical Activity Questionnaire - Short Form; IPOP: Instituto Português de Oncologia do Porto (Portuguese Oncology Institute of Porto); LMM: Linear Mixed Model; MBCR: Mindfulness-Based Cancer Recovery:

MBCT: Mindfulness-Based Cognitive Therapy; MBIs: Mindfulness-Based
Interventions; MBSR: Mindfulness-Based Stress Reduction; NCCN: National Comprehensive Cancer Network; PSA: Prostate-Specific Antigen;

PTGI: Posttraumatic Growth Inventory; RCT: Randomized Controlled Trial; SPIRIT: Standard Protocol Items: Recommendations for Intervention Trials; SSSS: Satisfaction with Social Support Scale; TAU: Treatment As Usual; TNF: Tumour Necrosis Factor; WHOQOL-Bref: World Health Organization Quality of Life - Bref

\section{Supplementary Information}

The online version contains supplementary material available at https://doi. org/10.1186/s13063-022-06045-x.

\section{Additional file 1.}

\section{Acknowledgements}

We would like to acknowledge other professionals, teams, and services of the IPOP for supporting the preparation and implementation of the current clinical study. We also would like to thank other teams involved in the MindGAP consortium.

\section{Authors' contributions}

ERS, CJ, and RH contributed to the design of the study and its coordination. GS conceived the idea of studying the effect of meditation on EVs. GS, ERS, and RJT worked on the mindfulness protocol. CJ, CCM, CL, and SMR ensure the blood sample management, processing, and logistics. DRP and ES participate in the recruitment of participants, data collection, compilation, and data management. RC contributed to data analysis and statistics. LEC is a scientific consultant for Mindfulness research. SJV's and GB's contribution is on brain-derived EV's characterization. All authors participate in data analysis and interpretation, and preparation of scientific reports and outputs. DRP drafted the initial version of the manuscript that all authors read and revised, resulting in the approval of the current final version. For the current and future publications associated with this protocol, the guidelines from the Committee on Publication Ethics (COPE) guidelines to determine authorship will be considered.

\section{Funding}

This study is funded by the European Commission, Horizon 2020, H2020FETOPEN-2018-2020, programme Novel ideas for radically new Technologies RIA. Research and Innovation, Action proposal number 829040 . The funding gives autonomy to the research teams with respect to study design, data collection, management, analysis, and interpretation, as well as in terms of writing and submitting study reports.

\section{Availability of data and materials}

This study was submitted and analysed by the IPOP's data protection officer (Ref. - 137/2020). The final trial dataset will only be accessed by the researchers involved in the study. Data will not be publicly available. Nonetheless, some data will be shared with other partners of the MindGAP project and might be made available to other researchers upon reasonable request to the research team.

\section{Declarations}

\section{Ethics approval and consent to participate}

The current clinical study was submitted and approved by the IPOP ethics committee (Ref. CES. 327A/029). Informed consent from all participants will be obtained prior to their enrolment.

\section{Consent for publication}

A model of consent form can be obtained upon request.

\section{Competing interests}

The authors declare that they have no competing interests.

\section{Author details}

${ }^{1}$ Psychology Service, Portuguese Oncology Institute of Porto (IPOP), Rua Dr. António Bernardino de Almeida, 4200-072 Porto, Portugal. ${ }^{2}$ Cancer Genetics Group, Research Centre of Portuguese Oncology Institute of Porto (CI-IPOP), 
Rua Dr. António Bernardino de Almeida, 4200-072 Porto, Portugal. ${ }^{3}$ RISE@CI-IPOP (Health Research Network), Portuguese Oncology Institute of Porto (IPOP), Rua Dr. António Bernardino de Almeida, 4200-072 Porto, Portugal. ${ }^{4}$ Porto Comprehensive Cancer Centre (Porto.CCC), Rua Dr. António Bernardino de Almeida, 4200-072 Porto, Portugal. ${ }^{5}$ Cancer Biology and Epigenetics Group, IPO Porto Research Center (GEBC CI-IPOP), Portuguese Oncology Institute of Porto (IPOP), Rua Dr. António Bernardino de Almeida, 4200-072 Porto, Portugal. ${ }^{6}$ Cancer Epidemiology Group-Research Center, Portuguese Oncology Institute of Porto (IPOP), Rua Dr. António Bernardino de Almeida, 4200-072 Porto, Portugal. ${ }^{7}$ Department of Epidemiology, Portuguese Oncology Institute of Porto (IPOP), Rua Dr. António Bernardino de Almeida, 4200-072 Porto, Portugal. ${ }^{8}$ CINEICC, Faculty of Psychology and Educational Sciences, University of Coimbra, Rua do Colégio Novo, 3000-115 Coimbra, Portugal. ${ }^{9}$ REACH, Mental Health Clinic, Rua de Camões, $218,4^{\circ}$ andar, sala 2, 4000-138 Porto, Portugal. ${ }^{10}$ Department of Oncology, University of Calgary, Calgary, AB T2N 3C1, Canada. " ${ }^{11}$ isease Networks Research Unit, Laboratory of Developmental Biology, Faculty of Biochemistry and Molecular Medicine, Infotech Oulu, Kvantum Institute, University of Oulu, 90570 Oulu, Finland. '2BioMark@UC, Department of Chemical Engineering, Faculty of Sciences and Technology, University of Coimbra, Rua Sílvio Lima, 3030-790 Coimbra, Portugal. ${ }^{13}$ BioMark Sensor Research/CEB, Centre of Biological Engineering of Minho University, Campus de Gualtar, 4710-057 Braga, Portugal. ${ }^{14}$ Department of Pathology and Molecular Immunology, Institute of Biomedical Sciences Abel Salazar, University of Porto (ICBAS-UP), Rua de Jorge Viterbo Ferreira, 228, 4050-313 Porto, Portugal. ${ }^{15}$ Department of Pathology, Portuguese Oncology Institute of Porto (IPOP), Rua Dr. António Bernardino de Almeida, 4200-072 Porto, Portugal.

Received: 13 October 2021 Accepted: 19 January 2022

Published online: 05 February 2022

\section{References}

1. World Health Organization (WHO). Cancer. 2018. https://www.who.int/newsroom/fact-sheets/detail/cancer. Accessed 7 Jan 2021.

2. World Health Organization (WHO). Global Cancer Observatory. 2021. https:// gco.iarc.fr/. Accessed 7 Jan 2021.

3. Bergerot CD, Araujo TCCF. Assessment of distress and quality of life of cancer patients over the course of chemotherapy. Investig y Educ en Enfermería. 2014;32(2):216-24. https://doi.org/10.17533/udea.iee.v32n2a04.

4. Harrington CB, Hansen JA, Moskowitz M, Todd BL, Feuerstein M. It's not over when it's over: long-term symptoms in cancer survivors-a systematic review. Int J Psychiatry Med. 2010;40(2):163-81. https://doi. org/10.2190/PM.40.2.c.

5. Muzzatti B, Bomben F, Flaiban C, Piccinin M, Annunziata MA. Quality of life and psychological distress during cancer: a prospective observational study involving young breast cancer female patients. BMC Cancer. 2020;20(1):758. https://doi.org/10.1186/s12885-020-07272-8.

6. Ravindran OS, Shankar A, Murthy T. A comparative study on perceived stress, coping, quality of life, and hopelessness between cancer patients and survivors. Indian J Palliat Care. 2019;25(3):414-20. https://doi.org/10.4103/ IJPC.IJPC_1_19.

7. National Comprehensive Cancer Network. NCCN guidelines for patients: distress during cancer care. 2020. https://www.nccn.org/patients/guidelines/ content/PDF/distress-patient.pdf. Accessed 7 Jan 2021.

8. Riba MB, Donovan KA, Andersen B. Braun li, Breitbart WS, Brewer BW, et al. Distress management, version 3.2019. JNCCN J Natl Compr Cancer Netw. 2019;17(10):1229-49. https://doi.org/10.6004/jnccn.2019.0048.

9. Ownby KK. Use of the Distress thermometer in clinical practice. J Adv Pract Oncol. 2019;10(2):175-9. https://doi.org/10.6004/jadpro.2019.10.2.7

10. Cillessen L, Johannsen M, Speckens AEM, Zachariae R. Mindfulness-based interventions for psychological and physical health outcomes in cancer patients and survivors: a systematic review and meta-analysis of randomized controlled trials. Psychooncology. 2019;28(12):2257-69. https://doi.org/10.1 002/pon.5214.

11. Xunlin N, Lau Y, Klainin-Yobas P. The effectiveness of mindfulness-based interventions among cancer patients and survivors: a systematic review and meta-analysis. Support Care Cancer. 2020;28(4):1563-78. https://doi.org/10.1 007/s00520-019-05219-9.

12. Kabat-Zinn J. Mindfulness. Mindfulness. 2015;6(6):1481-3. https://doi.org/10.1 007/s12671-015-0456-X.
13. Baer RA. Mindfulness training as a clinical intervention: a conceptual and empirical review. Clin Psychol Sci Pract 2003;10(2):125-143. https://doi.org/1 0.1093/clipsy.bpg015

14. Matis J, Svetlak M, Slezackova A, Svoboda M, Šumec R. Mindfulness-based programs for patients with cancer via eHealth and mobile health: systematic review and synthesis of quantitative research. J Med Internet Res. 2020;22(11):e20709. https://doi.org/10.2196/20709.

15. Lau MA, Segal Z V. Mindfulness-based cognitive therapy as a relapse prevention: approach to depression. In: Witkiewitz K, Marlatt G, editors. Therapist's guide to evidence-based relapse prevention. London: Academic Press; 2007. p. 73-90.

16. Carlson LE, Tamagawa R, Stephen J, Drysdale E, Zhong L, Speca M. Randomized-controlled trial of mindfulness-based cancer recovery versus supportive expressive group therapy among distressed breast cancer survivors (MINDSET): long-term follow-up results. Psychooncology. 2016; 25(7):750-9. https://doi.org/10.1002/pon.4150.

17. Bower JE, Crosswell AD, Stanton AL, Crespi CM, Winston D, Arevalo J, et al. Mindfulness meditation for younger breast cancer survivors: a randomized controlled trial. Cancer. 2015;121(8):1231-40. https://doi.org/10.1002/cncr.2 9194.

18. Haller H, Winkler MM, Klose P, Dobos $G$, Kümmel S, Cramer H. Mindfulnessbased interventions for women with breast cancer: an updated systematic review and meta-analysis. Acta Oncol. 2017;56(12):1665-76. https://doi.org/1 0.1080/0284186X.2017.1342862.

19. Howarth A, Smith JG, Perkins-Porras L, Ussher M. Effects of brief mindfulness-based interventions on health-related outcomes: a systematic review. Mindfulness. 2019;10(3):1957-68. https://doi.org/10.1007/s12671-01901163-1.

20. Oberoi S, Yang J, Woodgate RL, Niraula S, Banerji S, Israels SJ, et al. Association of mindfulness-based interventions with anxiety severity in adults with cancer: a systematic review and meta-analysis. JAMA Netw Open. 2020;3(8):e2012598. https://doi.org/10.1001/jamanetworkopen.2020.12 598.

21. Kinner EM, Armer JS, McGregor BA, Duffecy J, Leighton S, Corden ME, et al. Internet-based group intervention for ovarian cancer survivors: feasibility and preliminary results. JMIR Cancer. 2018;4(1):e1. https://doi.org/10.2196/ca ncer.8430.

22. Subnis UB, Farb NAS, Piedalue KAL, Speca M, Lupichuk S, Tang PA, et al. A smartphone app-based mindfulness intervention for cancer survivors: protocol for a randomized controlled trial. JMIR Res Protoc. 2020;9(5): e15178. https://doi.org/10.2196/15178.

23. Zernicke KA, Campbell TS, Speca M, McCabe-Ruff K, Flowers S, Dirkse DA, et al. The eCALM Trial-eTherapy for cancer applying mindfulness: online mindfulness-based cancer recovery program for underserved individuals living with cancer in Alberta: protocol development for a randomized waitlist controlled clinical trial. BMC Complement Altern Med. 2013;13(1):34. https://doi.org/10.1186/1472-6882-13-34.

24. Tate KJ, Newbury-Birch D, McGeechan GJ. A systematic review of qualitative evidence of cancer patients' attitudes to mindfulness. Eur J Cancer Care. 2018;27(2):e12783. https://doi.org/10.1111/ecc.12783.

25. Golită S, Băban A. A systematic review of the effects of internet-based psychological interventions on emotional distress and quality of life in adult cancer patients. J Evidence-Based Psychother. 2019;19(2):47-78. https://doi. org/10.1016/j.jpsychores.2018.03.064.

26. Fu Z, Burger H, Arjadi R, Bockting CLH. Effectiveness of digital psychological interventions for mental health problems in low-income and middle-income countries: a systematic review and meta-analysis. The Lancet Psychiatry 2020; 7(10):851-864. https://doi.org/10.1016/S2215-0366(20)30256-X

27. Wang Y, Lin Y, Chen J, Wang C, Hu R, Wu Y. Effects of internet-based psychoeducational interventions on mental health and quality of life among cancer patients: a systematic review and meta-analysis. Support Care Cancer. 2020; 28(6):2541-52. https://doi.org/10.1007/s00520-020-05383-3.

28. Linardon J. Can acceptance, mindfulness, and self-compassion be learned by smartphone apps? A systematic and meta-analytic review of randomized controlled trials. Behav Ther. 2020;51(4):646-58. https://doi.org/10.1016/j. beth.2019.10.002.

29. Jongerius C, Russo S, Mazzocco K, Pravettoni G. Research-tested mobile apps for breast cancer care: systematic review. JMIR Mhealth Uhealth. 2019; 21(2):e10930. https://doi.org/10.2196/10930.

30. Carlson LE, Subnis UB, Piedalue KAL, Vallerand J, Speca M, Lupichuk S, et al. The ONE-MIND Study: rationale and protocol for assessing the effects of 
ONlinE MINDfulness-based cancer recovery for the prevention of fatigue and other common side effects during chemotherapy. Eur J Cancer Care. 2019;28(4):e13074. https://doi.org/10.1111/ecc.13074.

31. Compen FR, Bisseling EM, Schellekens MPJ, Jansen ETM, Lee MLV, Speckens AEM. Mindfulness-based cognitive therapy for cancer patients delivered via internet: qualitative study of patient and therapist barriers and facilitators. J Med Internet Res. 2017;19(12):e407. https://doi.org/10.2196/jmir.7783.

32. Wolvers MD, Bruggeman-Everts FZ, Van der Lee ML, Van de Schoot R, Vollenbroek-Hutten MM. Effectiveness, mediators, and effect predictors of internet interventions for chronic cancer-related fatigue: the design and an analysis plan of a 3-armed randomized controlled trial. JMIR Res Protoc. 2015;4(2):e77. https://doi.org/10.2196/resprot.4363.

33. Kubo A, Kurtovich E, McGinnis MA, Aghaee S, Altschuler A, Quesenberry C, et al. Pilot pragmatic randomized trial of mHealth mindfulness-based intervention for advanced cancer patients and their informal caregivers. Psychooncology. 2020. https://doi.org/10.1002/pon.5557.

34. Toivonen K, Hermann M, White J, Speca M, Carlson LE. A mixed-method, multi-perspective investigation of barriers to participation in mindfulnessbased cancer recovery. Mindfulness. 2020;11(10):2325-37. https://doi.org/1 0.1007/s12671-020-01461-z.

35. Torous J, Myrick KJ, Rauseo-Ricupero N, Firth J. Digital mental health and COVID-19: using technology today to accelerate the curve on access and quality tomorrow. J Med Internet Res. 2020;7(3):e18848. https://doi.org/10.21 96/18848.

36. Kuderer NM, Choueiri TK, Shah DP, Shyr Y, Rubinstein SM, Rivera DR, et al. Clinical impact of COVID-19 on patients with cancer (CCC19): a cohort study. Lancet 2020;395(10241):1907-1918. https://doi.org/10.1016/S0140-673 6(20)31187-9

37. Schade EC, Elkaddoum R, Kourie HR. The psychological challenges for oncological patients in times of COVID-19 pandemic: telemedicine, a solution? Futur Oncol. 2020;16(29). https://doi.org/10.2217/fon-2020-0552

38. Spijkerman MPJ, Pots WTM, Bohlmeijer ET. Effectiveness of online mindfulness-based interventions in improving mental health: a review and meta-analysis of randomised controlled trials. Clin Psychol Rev. 2016;45:10214. https://doi.org/10.1016/j.cpr.2016.03.009.

39. Zhang $Y$, Xue J, Huang Y. A meta-analysis: internet mindfulness-based interventions for stress management in the general population. Medicine. 2020;99(28):e20493. https://doi.org/10.1097/MD.0000000000020493.

40. Bruggeman-Everts FZ, Wolvers MDJ, van de Schoot R, Vollenbroek-Hutten MMR, Van der Lee ML. Effectiveness of two web-based interventions for chronic cancer-related fatigue compared to an active control condition: results of the "fitter na kanker" randomized controlled trial. J Med Internet Res. 2017;19(10):e336. https://doi.org/10.2196/jmir.7180.

41. Compen F, Bisseling E, Schellekens M, Donders R, Carlson L, van der Lee M, et al. Face-to-face and internet-based mindfulness-based cognitive therapy compared with treatment as usual in reducing psychological distress in patients with cancer: a multicenter randomized controlled trial. J Clin Oncol. 2018;36(23):2413-21. https://doi.org/10.1200/JCO.2017.76.5669.

42. Cillessen L, Schellekens MPJ, Van de Ven MOM, Donders ART, Compen FR, Bisseling EM, et al. Consolidation and prediction of long-term treatment effect of group and online mindfulness-based cognitive therapy for distressed cancer patients. Acta Oncol. 2018;57(10):1293-302. https://doi. org/10.1080/0284186X.2018.1479071.

43. Bruggeman Everts FZ, van der Lee ML, de Jager Meezenbroek E. Web-based individual mindfulness-based cognitive therapy for cancer-related fatigue - a pilot study. Internet Interv. 2015;2(2):200-13. https://doi.org/10.1016/j. invent.2015.03.004.

44. Kubo A, Altschuler A, Kurtovich S, Laurent CA, Kolevska T, Li Y, et al. A pilot mobile-based mindfulness intervetion for cancer patients and their informal caregivers. Mindfulness. 2018;9(6):1885-94. https://doi.org/10.1007/s12671-01 8-0931-2.

45. Kubo A, Kurtovich E, McGinnis MA, Aghaee S, Altschuler A, Quesenberry C, et al. A randomized controlled trial of mHealth mindfulness intervention for cancer patients and informal cancer caregivers: a feasibility study within an integrated health care delivery system. Integr Cancer Ther. 2019;18: 1534735419850634. https://doi.org/10.1177/1534735419850634.

46. Messer D, Horan JJ, Larkey LK, Shanholtz CE. Effects of internet training in mindfulness meditation on variables related to cancer recovery. Mindfulness. 2019;10(3):2143-51. https://doi.org/10.1007/s12671-019-011 $82-y$.
47. Price-Blackshear MA, Pratscher SD, Oyler DL, Armer JM, Cheng AL, Cheng MX, et al. Online couples mindfulness-based intervention for young breast cancer survivors and their partners: a randomized-control trial. J Psychosoc Oncol. 2020;38(5):592-611. https://doi.org/10.1080/07347332.2020.1778150.

48. Russell L, Ugalde A, Orellana L, Milne D, Krishnasamy M, Chambers R, et al. A pilot randomised controlled trial of an online mindfulness-based program for people diagnosed with melanoma. Support Care Cancer. 2019;27(7): 2735-46. https://doi.org/10.1007/s00520-018-4574-6.

49. Zernicke KA, Campbell TS, Speca M, Mccabe-Ruff K, Flowers S, Carlson LE. A randomized wait-list controlled trial of feasibility and efficacy of an online mindfulness-based cancer recovery program: the eTherapy for cancer applying mindfulness trial. Psychosom Med. 2014;76(4):257-67. https://doi. org/10.1097/PSY.0000000000000053.

50. Zernicke KA, Campbell TS, Speca M, Ruff KMC, Flowers S, Tamagawa R, et al. The eCALM trial: eTherapy for cancer applying mindfulness. Exploratory analyses of the associations between online mindfulness-based cancer recovery participation and changes in mood, stress symptoms, mindfulness, posttraumatic growth, and spirituality. Mindfulness. 2016;7(5):1071-81. https://doi.org/10.1007/s12671-016-0545-5.

51. Mikolasek M, Witt CM, Barth J. Effects and implementation of a mindfulness and relaxation app for patients with cancer: mixed methods feasibility study. JMIR Cancer. 2021;7(1):e16785. https://doi. org/10.2196/16785.

52. Nissen ER, O'Connor M, Kaldo V, Højris I, Borre M, Zachariae R, et al. Internetdelivered mindfulness-based cognitive therapy for anxiety and depression in cancer survivors: a randomized controlled trial. Psychooncology. 2020; 29(1):68-75. https://doi.org/10.1002/pon.5237.

53. Milbury K, Weathers SP, Durrani S, Li Y, Whisenant M, Li J, et al. Online couple-based meditation intervention for patients with primary or metastatic brain tumors and their partners: results of a pilot randomized controlled trial. J Pain Symptom Manage. 2020;59(6):1260-7. https://doi. org/10.1016/j.jpainsymman.2020.02.004.

54. Compen F, Adang E, Bisseling E, van der Lee M, Speckens A. Cost-utility of individual internet-based and face-to-face mindfulness-based cognitive therapy compared with treatment as usual in reducing psychological distress in cancer patients. Psychooncology. 2020;29(2):294-303. https://doi. org/10.1002/pon.5246.

55. Reive $C$. The biological measurements of mindfulness-based stress reduction: a systematic review. Explore. 2019;15(4):295-307. https://doi.org/1 0.1016/j.explore.2019.01.001.

56. Rouleau CR, Garland SN, Carlson LE. The impact of mindfulness-based interventions on symptom burden, positive psychological outcomes, and biomarkers in cancer patients. Cancer Manag Res. 2015;7:121-31. https://doi. org/10.2147/CMAR.S64165.

57. Sanada K, Alda Díez M, Salas Valero M, Pérez-Yus MC, Demarzo MMP, MonteroMarín J, et al. Effects of mindfulness-based interventions on biomarkers in healthy and cancer populations: a systematic review. BMC Complement Altern Med. 2017;17(1):125. https:/doi.org/10.1186/s12906-017-1638-y.

58. Pedro J, Monteiro-Reis S, Carvalho-Maia C, Henrique R, Jerónimo C, Silva ER. Evidence of psychological and biological effects of structured mindfulnessbased interventions for cancer patients and survivors: a meta-review. Psychooncology. 2021;30(11):1836-48. https://doi.org/10.1002/pon.5771.

59. Davidson RJ, Kabat-Zinn J, Schumacher J, Rosenkranz M, Muller D, Santorelli $\mathrm{SF}$, et al. Alterations in brain and immune function produced by mindfulness meditation. Psychosom Med. 2003;65(4):564-70. https://doi. org/10.1097/01.psy.0000077505.67574.e3.

60. Lengacher CA, Reich RR, Kip KE, Barta M, Ramesar S, Paterson CL, et al. Influence of mindfulness-based stress reduction (MBSR) on telomerase activity in women with breast cancer (BC). Biol Res Nurs. 2014;16(4):438-47. https://doi.org/10.1177/1099800413519495.

61. Carlson LE, Beattie TL, Giese-Davis J, Faris P, Tamagawa R, Fick L, et al. Mindfulness-based cancer recovery and supportive-expressive therapy maintain telomere length relative to controls in distressed breast cancer survivors. Cancer. 2015;121(3):476-84. https://doi.org/10.1002/cncr.29063.

62. Carlson LE, Speca M, Patel KD, Goodey E. Mindfulness-based stress reduction in relation to quality of life, mood, symptoms of stress, and immune parameters in breast and prostate cancer outpatients. Psychosom Med. 2003;65(4):571-81. https://doi.org/10.1097/01.psy.0000074003.35911.41.

63. Witek Janusek L, Tell D, Mathews HL. Mindfulness based stress reduction provides psychological benefit and restores immune function of women 
newly diagnosed with breast cancer: a randomized trial with active control. Brain Behav Immun. 2019;80:358-73. https://doi.org/10.1016/j.bbi.2019.04.012

64. Saxe GA, Hébert JR, Carmody JF, Kabat-Zinn J, Rosenzweig PH, Jarzobski D, et al. Can diet in conjunction with stress reduction affect the rate of increase in prostate specific antigen after biochemical recurrence of prostate cancer? J Urol 2001;166(6):2202-2207. https://doi.org/10.1016/ S0022-5347(05)65535-8

65. Cheng L, Doecke JD, Sharples RA, Villemagne VL, Fowler CJ, Rembach A et al. Prognostic serum miRNA biomarkers associated with Alzheimer's disease shows concordance with neuropsychological and neuroimaging assessment. Mol Psychiatry. 2015;20(10):1188-96. https://doi.org/10.1038/ mp.2014.127.

66. Liu W, Bai X, Zhang A, Huang J, Xu S, Zhang J. Role of exosomes in central nervous system diseases. Front Mol Neurosci. 2019;12:240. https://doi.org/1 0.3389/fnmol.2019.00240.

67. Saeedi S, Israel S, Nagy C, Turecki G. The emerging role of exosomes in mental disorders. Transl Psychiatry. 2019;9(1):122. https://doi.org/10.1038/ s41398-019-0459-9.

68. Simeone P, Bologna G, Lanuti P, Pierdomenico L, Guagnano MT, Pieragostino D, et al. Extracellular vesicles as signaling mediators and disease biomarkers across biological barriers. Int J Mol Sci. 2020;21(7):2514. https://doi.org/10.3390/ijms21072514.

69. Whiteside TL. Tumor-derived exosomes and their role in cancer progression. Adv Clin Chem. 2016;74:103-41. https://doi.org/10.1016/bs.acc.2015.12.005.

70. Becker A, Thakur BK, Weiss JM, Kim HS, Peinado H, Lyden D. Extracellular vesicles in cancer: cell-to-cell mediators of metastasis. Cancer Cell. 2016; 30(6):836-48. https://doi.org/10.1016/j.ccell.2016.10.009.

71. Xu R, Rai A, Chen M, Suwakulsiri W, Greening DW, Simpson RJ. Extracellular vesicles in cancer — implications for future improvements in cancer care. Nat Rev Clin Oncol. 2018;15(10):617-38. https:/doi.org/10.1038/s41571-018-0036-9.

72. Bebelman MP, Smit MJ, Pegtel DM, Baglio SR. Biogenesis and function of extracellular vesicles in cancer. Pharmacol Ther. 2018;188:1-11. https://doi. org/10.1016/j.pharmthera.2018.02.013.

73. Hu T, Wolfram J, Srivastava S. Extracellular vesicles in cancer detection: hopes and hypes. Trends in Cancer. 2021;7(2):122-33. https://doi.org/10.101 6/j.trecan.2020.09.003.

74. Hill AF. Extracellular vesicles and neurodegenerative diseases. J Neurosci. 2019:39(47):9269-73. https://doi.org/10.1523/JNEUROSCI.0147-18.2019.

75. Ilgın C, Topuzoğlu A. Extracellular vesicles in psychiatry research in the context of RDoC criteria. Psychiatry Investig. 2018;15(11):1011-8. https://doi. org/10.30773/pi.2018.09.17.

76. Monteiro-Reis S, Carvalho-Maia C, Bart G, Vainio SJ, Pedro J, Silva ER, et al. Secreted extracellular vesicle molecular cargo as a novel liquid biopsy diagnostics of central nervous system diseases. Int J Mol Sci. 2021;22(6): 3267. https://doi.org/10.3390/ijms22063267.

77. MindGAP project. https://mindgap-fet-open.eu. Accessed 7 Jan 2021.

78. The Global Cancer Observatory. Portugal - source Globocan 2020. 2020. https://gco.iarc.fr/today/data/factsheets/populations/620-portugal-factsheets.pdf. Accessed 7 Jan 2021.

79. Nissen ER, Zachariae R, O'Connor M, Kaldo V, Jørgensen CR, Højris I, et al. Internet-delivered mindfulness-based cognitive therapy for anxiety and depression in cancer survivors: predictors of treatment response. Internet Interv. 2021;23:100365. https://doi.org/10.1016/j.invent.2021.100365.

80. Sun H, Thapa S, Wang B, Fu X, Yu S. A systematic review and meta-analysis of the distress thermometer for screening distress in Asian patients with cancer. J Clin Psychol Med Settings. 2021;28(2):212-20. https://doi.org/10.1 007/s10880-020-09705-9.

81. Thapa S, Sun H, Pokhrel G, Wang B, Dahal S, Yu S. Performance of distress thermometer and associated factors of psychological distress among Chinese cancer patients. J Oncol. 2020;2020:3293589. https://doi.org/10.1155/2020/3293589.

82. Faul F, Erdfelder E, Lang A, Buchner A. G*Power 3: a flexible statistical power analysis program for the social, behavioral, and biomedical sciences. Behav Res Methods. 2007;39(2):175-91. https://doi.org/10.3758/BF03193146.

83. Cohen J. Statistical power analysis for the behavioral sciences. 2nd ed. Hillsdale, NJ: Lawrence Erlbaum Associates; 1988.

84. Bisseling E, Cillessen L, Spinhoven P, Schellekens M, Compen F, Van Der Lee $M$, et al. Development of the therapeutic alliance and its association with internet-based mindfulness-based cognitive therapy for distressed cancer patients: secondary analysis of a multicenter randomized controlled trial. J Med Internet Res. 2019;21(10):e14065. https://doi.org/10.2196/14065.
85. Segal Z V., Williams M, Teasdale J. Mindfulness-based cognitive therapy for depression. 2nd ed. Guilford Publications; 2013.

86. Kabat-Zinn J. Mindfulness-based stress reduction (MBSR). Authorized curriculum guide. 2017; https://mindfulness.nhsggc.org.uk/media/2105/ mbsr-curriculum-guide-2017.pdf.

87. Carlson LE. Mindfulness-based interventions for physical conditions: a narrative review evaluating levels of evidence. ISRN Psychiatry. 2012;2012(5): 651583. https://doi.org/10.5402/2012/651583.

88. Compen FR, Bisseling EM, Van der Lee ML, Adang EMM, Donders ART, Speckens AEM. Study protocol of a multicenter randomized controlled trial comparing the effectiveness of group and individual internet-based mindfulness-based cognitive therapy with treatment as usual in reducing psychological distress in cancer patients: the BeMind study. BMC Psychol. 2015;3(1):27. https://doi.org/10.1186/s40359-015-0084-1.

89. Bisseling EM, Schellekens MPJ, Spinhoven P, Compen FR, Speckens AEM, van der Lee ML. Therapeutic alliance-not therapist competence or group cohesion-contributes to reduction of psychological distress in group-based mindfulness-based cognitive therapy for cancer patients. Clin Psychol Psychother. 2019;26(3):309-18. https://doi.org/10.1002/ cpp.2352.

90. Williams JMG, Russell I, Russell D. Mindfulness-based cognitive therapy: further issues in current evidence and future research. J Consult Clin Psychol. 2008;76(3):524-9. https://doi.org/10.1037/0022-006X.76.3.524.

91. UK Network of Mindfulness Teacher Training Organisations. Good practice guidance for teachers. 2015. https://bamba.org.uk/wp-content/uploads/201 9/06/UK-MB-teacher-GPG-2015-final-2.pdf. Accessed 7 Jan 2021.

92. Parsons CE, Crane C, Parsons LJ, Fjorback LO, Kuyken W. Home practice in mindfulness-based cognitive therapy and mindfulness-based stress reduction: a systematic review and meta-analysis of participants' mindfulness practice and its association with outcomes. Behav Res Ther. 2017;95:29-41. https://doi.org/10.1016/j.brat.2017.05.004.

93. Baydoun M, Moran C, McLennan A, Piedalue KAL, Oberoi D, Carlson LE. Mindfulness-based interventions in cancer survivors: a systematic review of participants' adherence to home practice. Patient Prefer Adherence. 2021;15: 1225-42. https://doi.org/10.2147/PPA.S267064.

94. Mikolasek M, Witt CM, Barth J. Adherence to a mindfulness and relaxation self-care app for cancer patients: mixed-methods feasibility study. JMIR Mhealth Uhealth. 2018;6(12):e11271. https://doi.org/10.2196/11271.

95. Wells C, Malins S, Clarke S, Skorodzien I, Biswas S, Sweeney T, et al. Using smart-messaging to enhance mindfulness-based cognitive therapy for cancer patients: a mixed methods proof of concept evaluation. Psychooncology. 2020;29(1):212-9. https://doi.org/10.1002/pon.5256.

96. Maas A, Schellekens MPJ, van Woezik RAM, van der Lee ML. Therapist behaviours in a web-based mindfulness-based cognitive therapy (eMBCT) for chronic cancer-related fatigue - analyses of e-mail correspondence. Internet Interv. 2020;22:100355. https://doi.org/10.1016/ j.invent.2020.100355.

97. Glynn BA, Khoo EL, MacLeay HML, Duong A, Cantave R, Poulin PA. Exploring cancer patients' experiences of an online mindfulness-based program: a qualitative investigation. Mindfulness. 2020;11(7):1666-77. https://doi.org/1 0.1007/s12671-020-01380-z.

98. Elliot R, Slatick E, Urman M. Qualitative process research on psychotherapy: alternative strategies. In: Frommer J, Rennie DL, editors. Qualitative psychotherapy research: methods and methodology. Lengerisch: Pabst Science Publishers; 2001. p. 69-111.

99. Sales CMD, Gonçalves S, Silva IF, Duarte J, Sousa D, Fernandes E, et al. Portuguese adaptation of qualitative change process instruments. Paper presented at the European Meeting of the Society for Psychotherapy Research; 2007 Mar; Funchal, Portugal.

100. Lovibond SH, Lovibond PF. Manual for the Depression Anxiety Stress Scales. 2nd ed. Psychology Foundation: Sydney; 1995

101. Pais-Ribeiro JL, Honrado A, Leal I. Contribuição para o estudo de adaptação portuguesa das escalas de ansiedade, depressão e stress (EADS) de 21 itens de Lovibond e Lovibond. Psicol Saúde Doenças. 2004;5(2):229-39.

102. Carey M, Bryant J, Zucca A, Hall A, Grady A, Dilworth S, et al. How well do cancer survivor self-classifications of anxiety, depression and stress agree with a standardised tool? Results of a cross-sectional study. PLoS One. 2019; 14(9):e0222107. https://doi.org/10.1371/journal.pone.0222107.

103. Fox RS, Lillis TA, Gerhart J, Hoerger M, Duberstein P. Multiple group confirmatory factor analysis of the DASS-21 Depression and Anxiety Scales: 
how do they perform in a cancer sample? Psychol Rep. 2018;121(3):548-65. https://doi.org/10.1177/0033294117727747.

104. Fjorback LO, Arendt M, Ornbol E, Fink P, Walach H. Mindfulness-based stress reduction and mindfulness-based cognitive therapy - a systematic review of randomized controlled trials. Acta Psychiatr Scand. 2011;124(2):102-19. https://doi.org/10.1111/j.1600-0447.2011.01704.x.

105. Gross JJ, John OP. Individual differences in two emotion regulation processes: implications for affect, relationships, and well-Being. J Pers Soc Psychol. 2003;85(2):348-62. https://doi.org/10.1037/0022-3514.85.2.348.

106. Vaz FM. Diferenciação e regulação emocional na idade adulta: tradução e validação de dois instrumentos de avaliação para a população portuguesa [master's thesis on the Internet]. Braga, Portugal: Faculdade de Psicologia da Universidade do Minho; 2009. http://repositorium.sdum.uminho.pt/bitstrea m/1822/9898/1/tese.pdf

107. Preece DA, Becerra R, Robinson K, Gross JJ. The emotion regulation questionnaire: psychometric properties in general community samples. J Pers Assess. 2020;102(3):348-56. https://doi.org/10.1080/00223891.2018.1564319.

108. Brandão T, Schulz MS, Gross JJ, Matos PM. The emotion regulation questionnaire in women with cancer: a psychometric evaluation and an item response theory analysis. Psychooncology. 2017;26(10):1647-53. https://doi.org/10.1002/pon.4356.

109. Humphris GM, Watson E, Sharpe M, Ozakinci G. Unidimensional scales for fears of cancer recurrence and their psychometric properties: the FCR4 and FCR7. Health Qual Life Outcomes. 2018;16(1):30. https://doi.org/10.1186/s12 955-018-0850-X.

110. Yang Y, Humphris G, Sun H, Li W, Hao Y, Liu T, et al. Psychometric properties of the Chinese version fear of cancer recurrence questionnaire-7 (FCR-7). Prof Psychol Res Pract. 2019;50(6):376-83. https://doi.org/10.1037/ pro0000257.

111. Baer RA, Smith GT, Hopkins J, Krietemeyer J, Toney L. Using self-report assessment methods to explore facets of mindfulness. Assessment. 2006; 13(1):27-45. https://doi.org/10.1177/1073191105283504.

112. Baer RA, Smith GT, Lykins E, Button D, Krietemeyer J, Sauer S, et al. Construct validity of the five facet mindfulness questionnaire in meditating and nonmeditating samples. Assessment. 2008;15(3):329-42. https://doi. org/10.1177/1073191107313003.

113. Gregório S, Gouveia JP. Facetas de mindfulness: características psicométricas de um instrumento de avaliação. Psychologica. 2011;54(54):259-79. https:// doi.org/10.14195/1647-8606_54_10.

114. Karl JA, Prado SMM, Gračanin A, Verhaeghen P, Ramos A, Mandal SP, et al. The cross-cultural validity of the five-facet mindfulness questionnaire across 16 countries. Mindfulness. 2020;11(5):1226-37. https://doi.org/10.1007/s12 671-020-01333-6.

115. Heatherton TF, Kozlowski LT, Frecker RC, Fagerström K-O. The Fagerström test for nicotine dependence: a revision of the Fagerström tolerance questionnaire. Br J Addict. 1991;86(9):1119-27. https://doi.org/10.1111/j.13 60-0443.1991.tb01879.x.

116. Ferreira PL, Quintal C, Lopes I, Taveira N. Teste de dependência à nicotina: validação linguística e psicométrica do teste de Fagerström. Rev Port Saúde Pública. 2009;27(2):37-56.

117. Craig CL, Marshall AL, Sjöström M, Bauman AE, Booth ML, Ainsworth $B E$, et al. International physical activity questionnaire: 12-country reliability and validity. Med Sci Sports Exerc. 2003;35(8):1381-95. https://doi.org/10.1249/01. MSS.0000078924.61453.FB.

118. Campaniço HMPG. Validade simultânea do questionário internacional de actividade física através da medição objectiva da actividade física por actigrafia proporcional [master's thesis on the Internet]. Lisboa, Portugal: Faculdade de Motricidade Humana da Universidade de Lisboa; 2016. https://www.repository.utl.pt/bitstream/10400.5/11866/1/DISSERTA\%c3\%87\% c3\%830\%202016\%20Helena\%20Campani\%c3\%a7o.pdf

119. Tedeschi RG, Calhoun LG. The posttraumatic growth inventory: measuring the positive legacy of trauma. J Trauma Stress. 1996;9(3):455-71. https://doi. org/10.1007/BF02103658.

120. Silva SIM, Moreira HTC, Pinto SMA, Sousa MCC, Canavarro P. Cancro da mama e desenvolvimento pessoal e relational: estudo das características psicométricas do inventário de desenvolvimento pós-traumático (posttraumatic growth inventory) numa amostra de mulheres da população Portuguesa. Rev Iberoam Diagnostico y Eval Psicol. 2009:28(2):105-33.

121. Ramos C, Leal I, Marôco AL, Tedeschi RG. The posttraumatic growth inventory: factor structure and invariance in a sample of breast cancer patients and in a non-clinical sample. Span J Psychol. 2016;19:E64. https:// doi.org/10.1017/sjp.2016.65.

122. The WHOQOL Group. Development of the World Health Organization WHOQOL-BREF quality of life assessment. Psychol Med. 1998;28(3):551-8. https://doi.org/10.1017/s0033291798006667.

123. Skevington SM, Lofty M, O'Connell KA. The World Health Organization's WHOQOL-BREF quality of life assessment: psychometric properties and results of the international field trial. A report from the WHOQOL group. Qual Life Res. 2004;13(2):299-310. https://doi.org/10.1023/B:QURE.00000184 86.91360.00.

124. Serra AV, Canavarro MC, Simões MR, Pereira M, Gameiro S, Quartilho MJ, et al. Estudos psicométricos do instrumento de avaliação da qualidade de vida da Organização Mundial de Saúde (WHOQOL-Bref) para português de Portugal. Psiquiatr Clínica. 2006;27(1):41-9.

125. Moreira H, Silva S, Canavarro C. Qualidade de vida e ajustamento psicossocial da mulher com cancro da mama: do diagnóstico à sobrevivência. Psicol Saúde Doenças. 2008;9(1):165-84.

126. Silva S, Bettencourt D, Moreira H, Canavarro MC. Qualidade de vida de mulheres com cancro da mama nas diversas fases da doença: o papel de variáveis sociodemográficas, clínicas e das estratégias de coping enquanto factores de risco/protecão. Rev Port Saúde Publica. 2011;29(1):64-76. https:// doi.org/10.1016/50870-9025(11)70009-8

127. Gomes AA, Marques DR, Meia-Via AM, Meia-Via M, Tavares J, Silva CF, et al. Basic Scale on Insomnia complaints and Quality of Sleep (BaSIQS): reliability, initial validity and normative scores in higher education students. Chronobiol Int. 2015;32(3):428-40. https://doi.org/10.3109/07420528.2014. 986681.

128. Miller-Mendes M, Gomes AA, Marques DR, Clemente V, Azevedo MHP. BaSIQS - basic scale on insomnia complaints and quality of sleep: reliability, norms, validity, and accuracy studies, based on clinical and community samples. Chronobiol Int. 2019;36(5):644-56. https://doi.org/10.1080/0742052 8.2019.1578970.

129. Pais-Ribeiro J. Escala de Satisfação com o Suporte Social (ESSS). Análise Psicológica. 1999;17(3):547-58.

130. Marôco JP, Campos JADB, Vinagre MDG, Pais-Ribeiro JL. Adaptação transcultural Brasil-Portugal da escala de satisfação com o suporte social para estudantes do ensino superior. Psicol Reflex e Crit. 2014;27(2):247-56. https://doi.org/10.1590/1678-7153.201427205.

131. Barkham M, Leach C, Lucock M, Evans C, Margison F, Mellor-Clark J, et al. Service profiling and outcomes benchmarking using the COREOM: toward practice-based evidence in the psychological therapies. J Consult Clin Psychol. 2001;69(2):184-96. https://doi.org/10.1037//0022006x.69.2.184

132. Evans C, Connell J, Barkham M, Margison F, McGrath G, Mellor-Clark J, et al. Towards a standardised brief outcome measure: psychometric properties and utility of the CORE-OM. Br J Psychiatry. 2002;180(1):51-60. https://doi. org/10.1192/bjp.180.1.51.

133. Evans C, Mellor-Clark J, Margison F, Barkham M, Audin K, Connell J, et al. CORE: Clinical Outcomes in Routine Evaluation. J Ment Heal. 2000;9(3):24755. https://doi.org/10.1080/jmh.9.3.247.255.

134. Sales C, Moleiro CDM. Versão Portuquesa do CORE-OM: tradução, adaptação e estudo preliminar das suas propriedades psicométricas. Rev Psiquiatr Clin. 2012;39(2):54-9. https://doi.org/10.1590/50101-60832012 000200003

135. Cumming G. Understanding the new statistics: effect sizes, confidence intervals, and meta-analysis. New York, USA: Routledge; 2012. https://doi. org/10.4324/9780203807002.

136. Bates D, Mächler M, Bolker BM, Walker SC. Fitting linear mixed-effects models using Ime4. J Stat Softw. 2015;67(1):1-48. https://doi.org/10.18637/jss.v067.i01.

137. Kuznetsova A, Brockhoff PB, Christensen RHB. ImerTest Package: tests in linear mixed effects models. J Stat Softw. 2017;82(13):1-26. https://doi.org/1 0.18637/jss.v082.113.

138. Core R. Team. R: A language and environment for statistical computing. Vienna, Austria: R Foundation for Statistical. Computing. 2017; https://www. R-project.org/.

139. Braun V, Clarke V. Using thematic analysis in psychology. Qual Res Psychol. 2006;3(2):77-101. https://doi.org/10.1191/1478088706qp063oa.

140. Kiger ME, Varpio L. Thematic analysis of qualitative data: AMEE guide no, 131. Med Teach. 2020;42(8):846-54. https://doi.org/10.1080/0142159X.2020.1 755030. 
141. Clarke V, Braun V. Thematic analysis. In: Teo T, editor. Encyclopedia of critical psychology. New York: Springer US; 2014. p. 1947-52.

142. Castleberry A, Nolen A. Thematic analysis of qualitative research data: is it as easy as it sounds? Curr Pharm Teach Learn. 2018;10(6):807-15. https://doi. org/10.1016/j.cptl.2018.03.019.

143. Andersson G, Titov N. Advantages and limitations of Internet-based interventions for common mental disorders. World Psychiatry. 2014;13(1):411. https://doi.org/10.1002/wps.20083.

144. Lapa T, Vieira J. Divisões digitais em Portugal e na Europa. Portugal ainda à procura do comboio europeu? Sociol Line. 2019;21(21):62-82. https://doi. org/10.30553/sociologiaonline.2019.21.3.

145. Mendes-Santos C, Andersson G, Weiderpass E, Santana R. Mitigating COVID19 Impact on the Portuguese population mental health: the opportunity that lies in digital mental health. Front Public Heal. 2020;8:553345. https:// doi.org/10.3389/fpubh.2020.553345.

146. Holm LV, Hansen DG, Johansen C, Vedsted P, Larsen PV, Kragstrup J, et al. Participation in cancer rehabilitation and unmet needs: a population-based cohort study. Support Care Cancer. 2012;20(11):2913-24. https://doi.org/10.1 007/s00520-012-1420-0.

\section{Publisher's Note}

Springer Nature remains neutral with regard to jurisdictional claims in published maps and institutional affiliations.

Ready to submit your research? Choose BMC and benefit from:

- fast, convenient online submission

- thorough peer review by experienced researchers in your field

- rapid publication on acceptance

- support for research data, including large and complex data types

- gold Open Access which fosters wider collaboration and increased citations

- maximum visibility for your research: over $100 \mathrm{M}$ website views per year

At $\mathrm{BMC}$, research is always in progress.

Learn more biomedcentral.com/submissions 